\title{
REVISÃO SISTEMÁTICA, BIBLIOMÉTRICA, DIVERSIDADE BIOLÓGICA E AS PTERIDÓFITAS
}

\author{
Antônio Pereira Júnior ${ }^{1}$; Emmanuelle Rodrigues Pereira² \\ 1 Mestre em Ciências Ambientais. Universidade do Estado do Pará. \\ E-mail: antonio.junior@uepa.br. \\ 2 Administradora com habilitação em Comércio Exterior. Especialização em \\ Logística Empresarial e Comércio exterior e negócios internacionais. \\ Recebido em: 06/04/2018 - Aprovado em: 10/06/2018 - Publicado em: 20/06/2018 \\ DOI: 10.18677/EnciBio_2018A94
}

\begin{abstract}
RESUMO
A Conferência Rio-92, a criação das Unidades de Conservação no Brasil e a Conservação da Diversidade Biológica, devem ser prioridades nas pesquisas científicas. O objetivo dessa pesquisa foi efetuar revisão sistemática e bibliométrica acerca da evolução das pesquisas e publicações sobre a diversidade biológica de Pteridófitas nos estados do Amazonas e Pará. O método utilizado foi o dedutivo, com pesquisa analítica, quantitativa, qualitativa e exploratória. Utilizou-se 13 periódicos selecionados nas bases SCIELO (cinco), Periódicos CAPES (quatro) e Google Scholar (quatro) com Qualis B1 a B4. A técnica empregada foi gerada a partir da junção da Revisão Bibliográfica Sistemática - SBS Roadmap e Systematic Search Flow - SSF, além de quatro indicadores bibliométricos: publicações, fontes de publicações, autores e palavras-chave e, finalmente, três descritores: botânico, geográfico e político. Os dados documentais obedeceram ao recorte temporal entre 1992 a 2017. A análise dos dados obtidos indicou que 66 artigos científicos (Amazonas - 26, Pará, 40) apresentaram descritores seletivos; indicou também que os números de pesquisas realizadas em UC's, sobre Pteridophyta, foi mais efetiva em UC's no Pará (32) em nove Unidades de Conservação, do que no Amazonas (27) somente na Reserva da Floresta Ducke. Dessa forma, não houve avanço no uso das UC's, no estado do Amazonas e, no Pará, a contribuição para a conservação da diversidade de Pteridophyta é baixa em função do número de UC's, no Amazonas (81) e Pará (82).
\end{abstract}

PALAVRAS-CHAVE: Licófitas; monilófitas, Samambaias; Unidades de Conservação.

\section{SYSTEMATIC AND BIBLIOMETRIC REVIEW ON THE STUDY OF BIOLOGICAL DIVERSITY OR BIODIVERSITY OF PTERIDÓFITAS}

\section{ABSTRACT}

The Rio-92 Conference, the creation of Conservation Units in Brazil and the Conservation of Biological Diversity, should be priorities in scientific research. The objective of this research was to carry out a systematic and bibliometric review of the evolution of research and publications on the biological diversity of Pteridophytes in the states of Amazonas and Pará. The method used was deductive, with analytical, quantitative, qualitative and exploratory research. Thirteen selected journals were 
selected in the SCIELO (five), CAPES (four) and Google Scholar (four) journals with Qualis B1 to B4. The technique employed was generated from the junction of the Systematic Bibliographic Review - SBS Roadmap and Systematic Search Flow SSF, in addition to four bibliometric indicators: publications, sources of publications, authors and keywords, and finally three descriptors: botanical, geographic and political. The documentary data followed the time cut between 1992 and 2017. Analysis of the data indicated that sixty-six scientific articles (Amazonas - twenty-six, Pará, forty) presented selective descriptors; also indicated that the numbers of research carried out in PAs on Pteridophyta were more effective in PAs in Pará (thirty-two) in nine Conservation Units than in the Amazon (twenty-seven) only in the Ducke Forest Reserve. Thus, there was no advance in the use of PAs in the state of Amazonas, and in Pará, the contribution to the conservation of Pteridophyta diversity is low due to the number of PAs in Amazonas (eighty-one) and Pará (eighty- two).

KEYWORDS: Lycophytes, monophyly, Ferns; Conservation units.

\section{INTRODUÇÃO}

A revisão sistemática da literatura - RSL é um método de pesquisa que busca responder questionamentos teóricos por meio da análise do conhecimento acumulado pelos pesquisadores no conjunto de artigos de uma determinada área da ciência. A RSL busca compreender o "estado da arte" do assunto pesquisado e deve responder uma questão de pesquisa específica. A utilização da RSL é uma tentativa de apropriação do "estado da arte" quando esse está disperso num número muito grande de publicações (CONFORTO et al., 2011).

Nesse contexto, a revisão sistemática é um tipo de pesquisa que utiliza como fonte de dados, a literatura sobre determinado tema. Esse tipo de investigação disponibiliza um resumo de evidências relacionadas a estratégia de intervenção específica, mediante a aplicação de métodos explícitos e sistematizados de busca (MEDEIROS et al., 2015).

Uma forma dos autores melhorarem seus conhecimentos é verificar uma pesquisa produzida em seu domínio de conhecimento: avaliando artigos submetidos a revista ou congresso científico, participando de bancas para avaliação de dissertação de mestrado ou teses de doutorados (SLOMSKI et al., 2013).

Quanto a análise bibliométrica, esta perpassa por quatro etapas importantes, adicionais à etapa de formulação do problema de pesquisa: a escolha da literatura analisada, a avaliação dos dados coletados, a análise e interpretação das informações e a apresentação dos resultados, logo, a bibliometria é a medida quantitativa das publicações científicas de um pesquisador ou instituição em periódicos com seleção arbitrada, e a medida qualitativa dessas publicações por meio de indicadores que incluem estudos comparativos de publicações e citações (SOUZA; RIBEIRO, 2013).

Em relação as origens das negociações da Convenção sobre Diversidade Biológica - CDB, remontam a 1987, quando o Conselho de Governo do Programa das Nações Unidas para o Meio Ambiente - PNUMA, aprovou a Decisão n. 14/26, prevendo a convocação de um grupo de especialistas em diversidade biológica para realizar a harmonização das convenções existentes relacionadas ao tema. Influenciada por estes debates, a Assembleia Geral da Organização das Nações Unidas - ONU, aprovou a Resolução n. 43/196, decidindo pela realização de uma nova conferência que tratasse da questão ambiental. A Resolução n. 44/228 convocou a Conferência das Nações Unidas sobre Meio Ambiente e 
Desenvolvimento (Rio-92) para junho de 1992. A discussão acerca da diversidade biológica/biodiversidade surgiu no Rio de Janeiro (FERREIRA; SAMPAIO, 2013).

No estado do Amazonas, a maioria dos estudos realizados está restrito à região metropolitana de Manaus, mais especificamente à Reserva Florestal Adolfo Ducke. Além disso, a biogeografia de samambaias e licófitas é marcada por uma taxa endêmica muito baixa ou talvez ausente, em uma área muito grande (SAMPAIO et al., 2015).

No Pará, as áreas melhor amostradas estão, em geral, próximas aos grandes centros urbanos ou em Unidades de Conservação. Entre estas, encontra-se a Floresta Nacional - FLONA, de Caxiuanã. Além disso, com uma área de aproximadamente 318.000 hectares, a FLONA de Caxiuanã possui uma riqueza de ambientes, apresentando áreas de terra firme, manchas de vegetação savanoide, capoeira, florestas inundáveis (várzea e igapó), além de abundante vegetação aquática proporcionando, assim, condições favoráveis à ocorrência de uma grande diversidade de licófitas e samambaias. (PIETROBOM et al., 2015).

A perda e a fragmentação de habitat, exploração excessiva dos recursos naturais, invasão biológica e mudanças climáticas estão conduzindo muitas espécies à extinção (LEMES; LOYOLA, 2014). As mudanças climáticas podem tornar-se a maior ameaça à biodiversidade e muitos sistemas ecológicos já mostram seus efeitos (GARCIA et al., 2012). Com isso, a manutenção da diversidade biológica, pode sofrer perdas a partir de fenômenos antrópicos, pois, a redução de riqueza de espécies e da densidade dos indivíduos é resultante da redução da umidade do solo (MEDEIROS et al., 2014).

No Brasil, os trabalhos sobre a diversidade e a ecologia de pteridófitas ainda são poucos, a maioria realizada na Mata Atlântica (RODRIGUES et al., 2004). Na Amazônia brasileira, há poucas informações sobre Pteridófitas (SOUZA et al., 2003). Embora haja três famílias de samambaias (Pteridaceae, Dryopteridaceae e Polypodiaceae), diversificadas para a microrregião de Belém (SILVA; ROSÁRIO, 2008; TRAVASSOS et al., 2014), o Pará, apesar de ser o segundo maior estado da região Norte, com mais de $1.250 .000 \mathrm{~km}^{2}$ incluídos quase que totalmente no bioma amazônico, foram reportadas até ao momento, 237 espécies de pteridófitas, logo, há poucos trabalhos desenvolvidos, especificamente com pteridófitas (COSTA et al., 2006; COSTA; PIETROBOM, 2007).

Dessa maneira, o avanço do estudo sobre Pteridophyta no Amazonas e Pará, deve ser avaliado, em face da elevada concentração de diversidade biológica dessa flora que apresenta funções diversas na natureza (Ex.: retenção hídrica, indicador de salinização no solo, funções alelopáticas, etc.), em UC's, ou não. Isso justifica a realização dessa pesquisa, cujo objetivo foi obter uma resposta à seguinte questão: a Implantação da Convenção da Diversidade Biológica, em 1992, e das Unidades de Conservação, em 2000, intensificaram as pesquisas sobre Pteridófitas nos estados do Amazonas e Pará, e permitiu a identificação e conservação da diversidade biológica das Pteridófitas nesses estados?

\section{MATERIAL E MÉTODOS}

Os materiais utilizados foram dados pretéritos oriundos do levantamento de dados documentais que obedeceu um recorte temporal compreendido entre 1992 e 2017, ou seja, últimos 27 anos. Essa limitação deve-se ao início da preocupação mundial com a Conservação Biológica/Biodiversidade (Eco 92/Rio - 92), e a promulgação da Lei Federal n. 9.985, de 18 de julho de 2000, que institui o Sistema Nacional de Unidades de Conservação - SNUC. 
O método utilizado foi o dedutivo, pois, partiu-se de duas premissas verdadeiras (FANTINATO, 2015): a diversidade biológica necessita ser conservada e as pteridófitas pois, dentre as funções exercidas, está a de indicadoras ambientais. A natureza da pesquisa foi aplicada (PRODANOV; FREITAS, 2013) porque irá gerar dados acerca da conservação de Pteridophyta nos estados do Amazonas e Pará e permitiu uso de dados pretéritos, logo, a abordagem foi quantitativa e qualitativa e com caráter exploratório, pois, analisou as publicações sobre estudos desse vegetal nesses dois estados.

Para a elaboração dessa pesquisa, foram associadas e adaptadas duas técnicas já existentes: (1) Revisão Bibliográfica Sistemática - RBS Roadmap (CONFORTO et al., 2011), etapas um, dois, três e sete, e (2) Systematic Search Flow - SSF (FERENHOF; FERNANDES, 2016), etapas seis e oito, associada a revisão bibliométrica porque é um método planejado para responder a uma pergunta norteadora (MACEDO et al., 2010). Essa junção proporcionou melhor adequação em busca da pergunta norteadora da pesquisa. Em seguida, aplicaram-se filtros para a obtenção dos artigos científicos que compuseram essa pesquisa (Figura 1).

Filtro 1 (Idioma) - Acesso aos dois repositórios temáticos (CAPES, GOOGLE SCHOLAR e Scielo e CAPES) para seleção dos periódicos cuja publicação envolva botânica para pré-seleção dos artigos científicos, apenas em português.

Filtro 2 (Botânica) - Pré-seleção dos artigos na língua portuguesa cujo tema da pesquisa envolva botânica, para exploração e formação de lista das palavras-chave que irão compor os descritores.

Filtro 3 (palavras temas) - Leitura e composição da lista com palavras-chave ${ }^{1}$ a partir da frequência de ocorrência no título, resumo e palavras-chave (MACEDO et al., 2010).

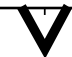

Filtro 4 (palavras mais frequentes) - Seleção das palavras-chave com maior frequência nos artigos pré-selecionados (título; resumo e palavras-chaves) no filtro 2. Cálculo da frequência relativa das mesmas em função do total (somaria da frequência absoluta), bem como da média aritmética de cada uma delas, com mínimo de $30 \%$ de fr.

Filtro 5 (palavras e descritores) - Composição dos três descritores ${ }^{2}$ em ordem de prioridade para a seleção final: geográficos, botânicos e políticos. Eles foram aplicados para a seleção final e consolidação dos dados obtidos

Filtro 6 - Aplicação dos descritores nos artigos pré-selecionados, seleção final e elaboração do artigo em tela.

FIGURA 1 - Aplicação dos seis filtros necessários à seleção e elaboração do artigo em tela. Fonte: autores (2018)

1 - A partir da base criada pela Lei Zipf ou Lei do Esforço Mínimo (SOUZA; RIBEIRO, 2013), que mensura a ocorrência de palavras em vários textos, o que gera uma lista ordenada das mesmas.

2 - Esses descritores foram associados a três operadores lógicos booleanos (string de buscas) and; or; not (FERENHORF; FERNANDES, 2016), e testados para verificação da funcionalidade: cita-se, como exemplo: Lycophyta and ferns; ferns or Licophyta. Isso foi efetuado para dar maior expansão e rapidez nessa seleção. 
Vale ressaltar que todas as publicações nacionais selecionadas durante o uso de descritores devem: atender, no mínimo, a três descritores; estar disponíveis gratuitamente na internet, indexadas, e possuírem o International Standard Serial Number - ISSN, ou o Digital Object Identifier - DOI, isso fornecerá maior segurança e credibilidade quanto as literaturas selecionadas e elaboração do documento final, com isso, optou-se pelo não uso de literatura cinzenta (PEREIRA; GALVÃO, 2014).

Para a análise bibliométrica, foram utilizados cinco indicadores: (1) frequência e fontes das publicações; (3) autores e coautores; (4) instituições e (5) palavraschave. O tratamento estatístico dos dados foi efetuado com o uso do software Excel (2016), com estatística descritiva (frequência absoluta relativa, média e desvio padrão).

\section{RESULTADOS E DISCUSSÃO}

\section{Pré seleção e avaliação dos periódicos}

A análise dos dados obtidos para a seleção dos periódicos nas três bases de pesquisa, indicou que 13 periódicos publicaram artigos científicos sobre botânica/Pteridophyta, no período compreendido entre 1992 a 2017. Os dados também indicaram que todos possuem ISSN e estão com as classificações dos Qualis Capes atualizadas (Quadro 1).

QUADRO 1 - Treze periódicos selecionados, e as bases onde se encontram cujas publicações envolvem o tema dessa pesquisa, número de publicações/ano, a fonte onde são encontrados e o QualisCapes.

\begin{tabular}{|l|c|c|c|}
\hline \multicolumn{1}{|c|}{ Periódico } & NPA & Fonte & QC $^{*}$ \\
\hline Acta Amazonica & 4 & SCIELO & B2 \\
\hline Acta Biológica Catarinense & 3 & GS & B4 \\
\hline Acta Botânica Brasílica & 4 & SCIELO & B2 \\
\hline Biota Amazônia & 4 & GS & B1 \\
\hline Biota Neotropica & 4 & SCIELO & B1 \\
\hline Biotemas & 4 & CAPES & B5 \\
\hline Bol. Mus. Para. Emilio Goeldi - CN & 3 & CAPES & B1 \\
\hline HOEHNHEA & 4 & SCIELO & B2 \\
\hline IAP - Pesquisas Botânica. & 1 & GS & B4 \\
\hline Revista Brasileira de Biociências & 4 & GS & B2 \\
\hline Revista Biológica Neotropical & 4 & CAPES & B3 \\
\hline Revista Brasileira de Botânica & 4 & SCIELO & B2 \\
\hline Rodriguésia & 4 & SCIELO & B1 \\
\hline
\end{tabular}

Legendas: Bol Mus. Para. Emílio Goeldi - CN: Boletim do Museu Paraense Emílio Goeldi - Ciências Naturais; NPA - Número de Publicações/ano; GS - Google Scholar; QC - Qualis Capes (*20162017)

Fonte: SCIELO, CAPES, UFRGS (2011)

Quanto ao volume de publicações, em cada um dos 13 periódicos analisados, os dados obtidos indicaram que os valores para as frequências absolutas (fi), situaram-se entre duas a 52 publicações, cujas médias oscilaram entre 0,15 a 4,0 (Tabela 1). 
TABELA 1 - Número de publicações por periódico entre 1992 e 2017.

\begin{tabular}{lcccccc}
\hline \multicolumn{1}{c}{ Periódicos } & $1992-2001$ & $2002-2011$ & $2012-2017$ & fi & fr(\%) & $\bar{x}$ \\
Acta Amazonica & 9 & 22 & 5 & 36 & 17,82 & 2,76 \\
Acta Botanica Brasilica & 4 & 14 & 3 & 21 & 10,4 & 1,61 \\
Acta Biológica Catarinense & 0 & 0 & 3 & 3 & 1,48 & 0,23 \\
Biota Amazônia & 0 & 0 & 3 & 3 & 1,48 & 0,23 \\
Biota Neotropica & 0 & 1 & 3 & 4 & 2,00 & 0,30 \\
Biotemas & 0 & 4 & 3 & 7 & 3,46 & 0,53 \\
Bol. Mus. Para. Emilio Goeldi-CN & 0 & 5 & 2 & 7 & 3,46 & 0,53 \\
Hoehnea & 0 & 13 & 8 & 21 & 10,4 & 1,61 \\
IAP - Pesquisas Botânica. & 0 & 10 & 30 & 40 & 19,80 & 3,07 \\
Revista Biológica Neotropical & 0 & 4 & 0 & 4 & 1,98 & 0,30 \\
Revista Brasileira de Biociências & 0 & 0 & 2 & 2 & 0,99 & 0,15 \\
Revista Brasileira de Botânica & 2 & 0 & 0 & 2 & 0,99 & 0,15 \\
Rodriguésia & 0 & 30 & 22 & 52 & 25,74 & 4 \\
Totais & 15 & 103 & 84 & 202 & 100 & \\
\hline
\end{tabular}

Fonte: autores (2018)

Quanto a análise estatística dos três períodos, esta indicou que os valores para as médias das publicações nos três períodos, situaram-se entre 1,2 a 5,9, os valores menores, ocorreram entre 1992 a 2001, e os mais elevados entre 2002 a 2011, além de revelar uma diminuição entre 2012 e 2017, porém, ressalte-se que esta década ainda não está conclusiva (Tabela 2).

TABELA 2 - Valores obtidos na análise estatista dos dados das publicações científicas entre 1992 e 2017 em 13 periódicos analisados.

\begin{tabular}{lccc}
\hline & $1992-2001$ & $2002-2011$ & $2012-2014$ \\
\hline Tamanho da amostra & 13 & 13 & 13 \\
Mínimo & 0,0 & 0,0 & 0,0 \\
Máximo & 9,0 & 30,0 & 30,0 \\
Média & 1,2 & 7,9 & 6,5 \\
Desvio Padrão & 2,6 & 9,5 & 9,1 \\
\hline
\end{tabular}

Fonte: autores (2018)

Em relação ao periódico mais prolífero, os dados indicaram que a Revista "Rodriguésia", com 52 publicações $(25,74 \%)$ foi mais efetiva. Vale ressaltar que tal periódico lançou dois suplementos para artigos sobre pteridófitas, um para a Reserva Ducke - AM (2005), e outro para a Flona Carajás - PA (2015), isso justifica o maior valor para a frequência relativa de publicações para esse periódico, bem como o valor encontrado, em média $(\bar{x}=4)$.

No estudo efetuado por Fonseca (2015), na Faculdade de Medicina do Porto, em Portugal, esse autor afirmou que o crescimento exponencial dos artigos científicos se deve aos fatores como o aumento da investigação, os avanços tecnológicos ou mesmo o reforço da importância do artigo científico. Em cerca de duas décadas passou-se da dificuldade de acesso à informação científica para a de imperiosidade de escolha de entre a imensa quantidade de artigos científicos produzidos. Como o estágio de pesquisas e publicações ocorridas entre 1992 e 2017, já apresenta média elevada $(7,9)$ a seleção para a preparação acerca da conservação de pteridófitas eleva-se.

Os dados analisados indicaram que, no período de 1992 a 2017, foram publicados, 202 artigos científicos sobre botânica, nos 13 periódicos selecionados, dos quais, $28(12,6 \%)$, foram artigos em língua estrangeira (inglês). Tais artigos foram descartados na aplicação do filtro 1 (idioma). Obteve-se então $174(86,13 \%)$ 
artigos para leitura e seleção das palavras mais frequentes para a composição dos descritores.

\section{FILTRO 2, 3 E 4 - TERMO BOTÂNICOS E LEITURA E BUSCA DAS PALAVRAS MAIS FREQUENTES PARA COMPOSIÇÃO DOS DESCRITORES}

Os dados obtidos e analisados indicaram quanto a busca de palavras mais frequentes contidas no título, resumo e palavras-chave, dos 174 artigos científicos pré-selecionados, os valores para as frequências das palavras de contexto botânico (pteridófitas/Pteridophyta; licófitas/Licophyta; samambaias, famílias, gêneros e espécies, estas três últimas, escritas em Latim), geográficos e políticos, situaram-se entre $1,5 \%$ a $53,8 \%$ (Tabela 3 ).

TABELA 3 - Seleção das palavras mais frequentes contidas no: título, resumo e palavraschave dos cento e oitenta e sete artigos científicos pré-selecionados.

\begin{tabular}{llcccccc}
\hline \multicolumn{1}{c}{ Palavras } & Titulo & Resumo & Palavras-chave & fi & frp & $\bar{x}$ \\
1 & Amazônia & 0 & 0 & 3 & 3 & 1,5 & 0,23 \\
2 & Belém & 1 & 2 & 0 & 2 & 1,5 & 0,15 \\
3 & Biodiversidade & 0 & 0 & 1 & 1 & 0,5 & 0,07 \\
4 & Corredores Ecológicos & 2 & 1 & 0 & 2 & 1,5 & 1,5 \\
5 & Diversidade & 0 & 0 & 4 & 4 & 2,0 & 0,30 \\
6 & Espécies - Latim & 8 & 60 & 7 & 85 & 37,7 & 6,53 \\
7 & Estados: Amazonas/AM & 1 & 0 & 0 & 1 & 0,5 & 0,07 \\
8 & Família - Latim & 36 & 53 & 18 & 107 & 53,8 & 8,23 \\
9 & Gênero - Latim & 13 & 50 & 12 & 75 & 37,7 & 5,76 \\
10 & Licófitas & 24 & 23 & 3 & 50 & 25,0 & 3,84 \\
11 & Lycophyta & 2 & 2 & 5 & 9 & 5,5 & 0,69 \\
12 & Manaus & 1 & 1 & 0 & 2 & 0,5 & 0,15 \\
13 & Monilófitas & 5 & 5 & 4 & 14 & 7,0 & 1,07 \\
14 & Monilophyta & 4 & 3 & 3 & 10 & 5,0 & 0,76 \\
15 & Pará /PA & 4 & 6 & 3 & 13 & 6,5 & 1,00 \\
16 & Pteridoflora & 5 & 2 & 0 & 7 & 5,0 & 0,53 \\
17 & Pteridófitas & 20 & 19 & 36 & 75 & 37,7 & 5,76 \\
18 & Pteridophyta & 18 & 3 & 6 & 30 & 13,5 & 2,30 \\
19 & Samambaias & 30 & 25 & 36 & 91 & 45,7 & 7,00 \\
21 & Unidades de Conservação & 35 & 22 & 5 & 62 & 31,1 & 4,76 \\
\hline
\end{tabular}

Legendas: $f i$ - frequência absoluta; frp - frequência relativa percentual; $\bar{x}$ : media

Fonte: autores (2018)

A análise dos dados obtidos indicou que as palavras: família $(\bar{x}=8,23)$, samambaias $(\bar{x}=7,00)$, gênero ( $\bar{x}=5,76)$, pteridófitas $(\bar{x}=5,76)$, espécie $(\bar{x}=6,53)$, todas de contexto botânico, foram as mais utilizadas pelos pesquisadores nas três seções analisadas. Em função da Lei de Zipf, tem-se o seguinte rank: baixa ordem para família, samambaia, gênero e pteridófitas, espécie e unidades de conservação, e alta ordem para as demais, ou seja, quanto maior a frequência menor será a ordem/rank.

$\mathrm{Na}$ pesquisa efetuada por Santos (2015), sobre análise bibliométrica, esse autor escreveu que, em um texto longo, existe uma relação entre a frequência e a posição na lista de palavras ordenadas, de acordo com a quantidade de ocorrência. $\mathrm{Na}$ pesquisa realizada em Paragominas, foi este o princípio norteador para relacionar as palavras mais frequentes e compor os descritores.

Em relação as unidades de conservação, citadas pelo nome oficial (Ex.: Reserva Ducke; Parque Ambiental de Belém), então consideradas como descritores 
políticos, devido a gestão estar a cargo da União, estados e municípios, os dados indicaram que estas foram citadas no título, resumo e palavras-chave $(\bar{x}=4,76)$ nos artigos científicos analisados. Com isso, verificou-se que a somatória das médias encontradas $(38,04)$ ultrapassava o mínimo exigido pela análise estatística média $(\bar{x}$ $=42,5 \%$ ), ou seja, $30 \%$.

\section{FILTRO CINCO - COMPOSIÇÃO DOS DESCRITORES}

Quanto a composição dos descritores (Quadro 2), a análise dos dados indicou que as palavras de maior frequência selecionadas e utilizadas para os descritores, proporcionam uma seleção mais efetiva quando associadas entre si, desde que as escolhas obedeçam a primeira e a segunda Lei de Zipf.

QUADRO 2 - Identificação dos três descritores utilizados para seleção dos artigos científicos utilizados nesta pesquisa.

\begin{tabular}{|c|l|}
\hline Descritores & \multicolumn{1}{|c|}{ Características } \\
\hline $\begin{array}{c}\text { Botânicos } \\
\text { (DB) }\end{array}$ & $\begin{array}{l}\text { - Pteridophyta; Pteridoflora, Lycophyta ou licófitas; samambaias; } \\
\text { Famílias/Gêneros/Espécies. As grafias podem ser latinizadas ou não. }\end{array}$ \\
\hline $\begin{array}{c}\text { Geográficos } \\
\text { (DG) }\end{array}$ & $\begin{array}{l}\text { - Manaus ou Amazonas, Belém ou Pará; Amazônia, desde que, no RESUMO } \\
\text { cite um dos estados como local da pesquisa. }\end{array}$ \\
\hline $\begin{array}{c}\text { Políticos } \\
\text { (DP) }\end{array}$ & $\begin{array}{l}\text { - Unidades de Conservação (Federal, Estadual e Municipal) sejam sobre } \\
\text { estas denominações, ou citações nominais das mesmas: Ex.: Parque } \\
\text { Ambiental de Belém; Reserva Ducke; Flora das cangas Serra dos Carajás) }\end{array}$ \\
\hline
\end{tabular}

Fonte: autores (2018)

\section{FILTRO SEIS - APLICAÇÃO DOS DESCRITORES}

Os dados obtidos após a aplicação dos descritores, indicaram que 108 (62\%) foram descartados por não atenderem as condições quanto a essas ferramentas necessárias à seleção, prioritariamente, os botânicos e geográficos, e 66 (37,93\%), atenderam a essa condição (Figura 1).

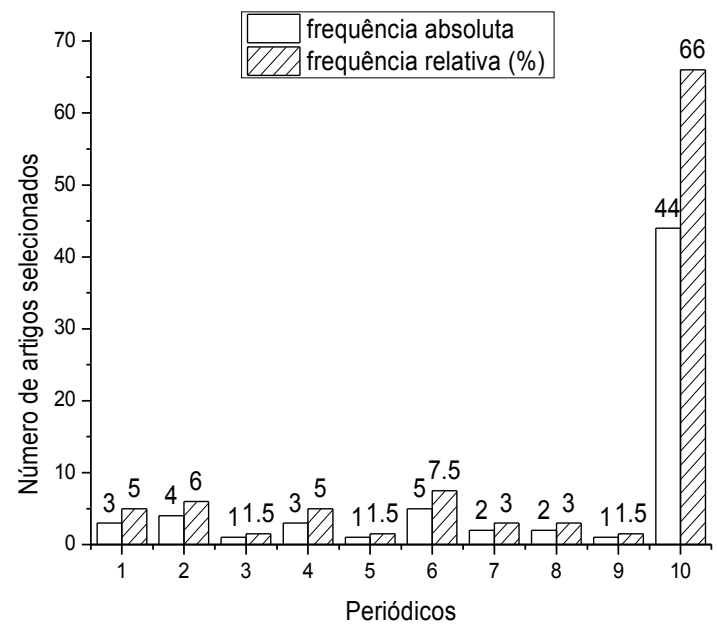

FIGURA 1 - Frequência absoluta e relativa dos artigos científicos selecionados e não selecionados, após a aplicação dos descritores pré-estabelecidos em cada um dos treze períodos objetos dessa pesquisa.

Fonte: autores (2018)

Legendas: 1 - Acta Amazonica; 2 - Acta botânica Brasilica; 3 -

Acta biologia Catarinense; 4 - Biota Amazônia; 5 - Biota

ENCICLOPÉDIA BIOSFERA, Centro Científico Conhecer - Goiânia, v.15 n.27; p.57 
neotropica; 6 - Boletim Museu Paraense Emílio Goeldi Ciências Naturais; 7 - Hoehnea; 8 - Pesquisas, botânica; 9 Revista Biológica Neotropical; 10 - Rodriguésia.

Os dados analisados sobre os artigos descartados e as justificativas indicaram que o fator preponderante para essa ação, foi a ausência dos descritores botânicos e geográficos no título, ou no resumo, ou nas palavras-chave, ou nos três setores analisados (Quadro 3).

QUADRO 3 - Periódicos analisados e as justificativas para a não seleção dos artigos nele publicados no período analisado (1992 a 2017).

\begin{tabular}{|c|c|}
\hline PERIÓDICOS & JUSTIFICATIVA PARA NÃO SELEÇÃO \\
\hline Acta Amazonica & $\begin{array}{l}\text { Todos os trinta e três artigos resultaram de } \\
\text { pesquisas botânicas e foram realizadas nos dois } \\
\text { estados pesquisados, porém, a linha da pesquisa } \\
\text { não foi sobre Pteridophyta. Onze destas pesquisas, } \\
\text { ocorreram em UC's (Seis no Amazonas; cinco no } \\
\text { Pará). }\end{array}$ \\
\hline $\begin{array}{l}\text { Acta biológica } \\
\text { Catarinense }\end{array}$ & $\begin{array}{l}\text { As duas publicações são resultados de pesquisas } \\
\text { com Pteridophyta, porém, tais pesquisas não } \\
\text { ocorreram em nenhum dos dois estados } \\
\text { pesquisados. Uma delas ocorreu em UC. }\end{array}$ \\
\hline $\begin{array}{l}\text { Acta Botânica } \\
\text { Brasilica }\end{array}$ & $\begin{array}{l}\text { Todos os dezessete artigos versam sobre } \\
\text { pesquisas com Pteridophyta, porém nenhuma delas } \\
\text { ocorreu nos dois estados analisados. Cinco delas, } \\
\text { ocorreram em UC's. }\end{array}$ \\
\hline Biota Neotropica & $\begin{array}{l}\text { Das três pesquisas, apenas uma foi efetuada sobre } \\
\text { Pteridófitas, porém não ocorreu em nenhum dos } \\
\text { dois estados pesquisados. }\end{array}$ \\
\hline Biotemas & $\begin{array}{l}\text { Todos os sete artigos são resultados de pesquisas } \\
\text { com Pteridophyta, porém, as pesquisas não } \\
\text { ocorreram nos dois estados pesquisados. Uma } \\
\text { delas ocorrem em uma UC. }\end{array}$ \\
\hline BMPEG-CN & $\begin{array}{l}\text { As duas pesquisas tiveram como foco, Pteridophyta, } \\
\text { porém náo foram efetuadas em nenhum dos dois } \\
\text { estados analisados. }\end{array}$ \\
\hline Hoehnea & $\begin{array}{l}\text { Todas estas publicações (19) resultaram de } \\
\text { pesquisas com Pteridophyta, porém nenhuma delas } \\
\text { foi realizada em um dos estados aqui analisados. } \\
\text { Destes, dezesseis foram realizados em UC's. }\end{array}$ \\
\hline Pesquisa Botânica & $\begin{array}{l}\text { Todas as trinta e oito pesquisas foram efetuadas } \\
\text { sobre Pteridophyta, porém nenhuma delas correu } \\
\text { em um dos estados objetos dessa pesquisa. Seis } \\
\text { delas, foram efetuadas em UC's. }\end{array}$ \\
\hline $\begin{array}{l}\text { Revista Biológica } \\
\text { Neotropical }\end{array}$ & $\begin{array}{l}\text { Os três artigos versam sobre Pteridophyta. Porém, } \\
\text { as pesquisas não ocorreram em um dos estados } \\
\text { objetos dessa pesquisa. }\end{array}$ \\
\hline $\begin{array}{l}\text { Revista Brasileira de } \\
\text { Biociências }\end{array}$ & $\begin{array}{l}\text { As duas pesquisas foram sobre Pteridophyta, mas, } \\
\text { novamente, náo foram efetuadas em um dos } \\
\text { estados aqui analisados. }\end{array}$ \\
\hline $\begin{array}{l}\text { Revista Brasileira de } \\
\text { Botânica }\end{array}$ & $\begin{array}{l}\text { Nenhuma das duas pesquisas foram efetuadas em } \\
\text { um dos dois estados pesquisados. Quatro delas } \\
\text { foram efetuadas em UC's. }\end{array}$ \\
\hline Rodriguésia & $\begin{array}{l}\text { As oito pesquisas têm como tema: Pteridophyta, } \\
\text { porém, não foram realizados nos dois estados } \\
\text { pesquisados; um, a pesquisa relata a evolução do } \\
\text { estudo na área (Carajás). Cinco delas, foram } \\
\text { realizadas em UC's. }\end{array}$ \\
\hline
\end{tabular}


Fonte: autores (2018).

A análise dos dados quanto a distribuição geográfica das pesquisas e publicações selecionadas, indicaram que $26(39,4 \%)$, estão relacionados ao estado do Amazonas (Quadro 4).

QUADRO 4 - Ano de publicação, autores, periódicos, título e palavras - chave dos artigos publicados sobre Pteridophyta no estado do Amazonas, entre 1992 e 2017.

\begin{tabular}{|c|c|c|c|}
\hline AP & Autores & Periódico & Título + Palavras chave* \\
\hline 1992 & $\begin{array}{l}\text { Castellani, E, } \\
\text { D. Freitas. C. } \\
\text { A. }\end{array}$ & $\begin{array}{l}\text { Acta bot. bras. } \\
\text { v. } 6, \text { n. } 1 \\
\text { p. } 41-48\end{array}$ & $\begin{array}{l}\text { Selagineláceas da Reserva Ducke (Manaus - AM) } \\
\text { *Selaginelaceae; florística. }\end{array}$ \\
\hline 2003 & $\begin{array}{l}\text { Souza. M. C. } \\
\text { Guillaumet, J. } \\
\text { L. } \\
\text { Aguiar, I. J. A. }\end{array}$ & $\begin{array}{l}\text { Acta Amaz. } \\
\text { v. } 33, \text { n. } 4 \\
\text { p. } 555-562\end{array}$ & $\begin{array}{l}\text { Ocorrência e distribuição de pteridófitas na Reserva } \\
\text { Florestal Walter Engler, Amazônia Central, Brasil. } \\
{ }^{*} \text { Pteridófitas, sub-bosque, habitat, hábito. }\end{array}$ \\
\hline $2005 a$ & $\begin{array}{l}\text { Costa, M. A. } \\
\text { S.; Prado, J. }\end{array}$ & $\begin{array}{l}\text { Rodriguésia } \\
\text { v. } 56, \text { n.86, p72- } \\
73\end{array}$ & $\begin{array}{l}\text { Flora Da Reserva Ducke, Amazonas, Brasil: } \\
\text { Pteridophyta - Metaxyaceae } \\
\text { "Ausente }\end{array}$ \\
\hline $2005 b$ & $\begin{array}{l}\text { Costa, M. A. } \\
\text { S.; Prado, J. }\end{array}$ & $\begin{array}{l}\text { Rodriguésia. } \\
\text { v. } 56, \text { n. } 86 \\
\text { p. } 74-75 .\end{array}$ & $\begin{array}{l}\text { Flora Da Reserva Ducke, Amazonas, Brasil: } \\
\text { Pteridophyta - Ophioglossaceae. } \\
{ }^{* A u s e n t e s .}\end{array}$ \\
\hline 2005 & $\begin{array}{l}\text { Freitas, C. A. } \\
\text { A. Prado, J. }\end{array}$ & $\begin{array}{l}\text { Acta bot. bras. } \\
\text { v. } 19, \text { n. } 2 \\
\text { p. } 399-406\end{array}$ & $\begin{array}{l}\text { Lista anotada das pteridófitas de florestas inundáveis } \\
\text { do alto Rio Negro, Município de Santa Isabel do Rio } \\
\text { Negro, AM, Brasil. } \\
\text { *Floresta Amazônica; Estado do Amazonas, } \\
\text { pteridófitas, samambaias, florística. }\end{array}$ \\
\hline 2005 & $\begin{array}{l}\text { Freitas, C. A. } \\
\text { A. Prado, J. }\end{array}$ & $\begin{array}{l}\text { Rodriguésia } \\
\text { v. } 56, \text { n. } 85 \\
\text { p. } 49-52.3\end{array}$ & $\begin{array}{l}\text { Flora Da Reserva Ducke, Amazonas, Brasil: } \\
\text { Pteridophyta - Dryopteridaceae } \\
{ }^{* A u s e n t e s .}\end{array}$ \\
\hline 2005 & $\begin{array}{l}\text { Freitas, C. A. } \\
\text { A. Windisch, P. } \\
\text { G. }\end{array}$ & $\begin{array}{l}\text { Rodriguésia } \\
\text { v. } 56, \text { n. } 85 \\
\text { p. } 67-68.3\end{array}$ & $\begin{array}{l}\text { Flora Da Reserva Ducke, Amazonas, Brasil: } \\
\text { Pteridophyta - Lycopyaceae } \\
\text { ^Ausentes. }\end{array}$ \\
\hline 2005 & $\begin{array}{l}\text { Hopkins. M J. } \\
\text { G. }\end{array}$ & $\begin{array}{l}\text { Rodriguésia } \\
\text { v. } 56, \text { n. } 86 \\
\text { p. } 9-253\end{array}$ & $\begin{array}{l}\text { Flora da Reserva Ducke, Amazonas, Brasil. } \\
{ }^{*} \text { Amazônia Central, floresta de terra firme; florística. }\end{array}$ \\
\hline 2005 & $\begin{array}{l}\text { Prado, J. } \\
\text { Freitas, C. A. } \\
\text { A. }\end{array}$ & $\begin{array}{l}\text { Rodriguésia } \\
\text { v. } 56, \text { n. } 86 \\
\text { p. } 35-37\end{array}$ & $\begin{array}{l}\text { Flora Da Reserva Ducke, Amazonas, Brasil: } \\
\text { Pteridophyta - Cyatheaceae. } \\
\text { ^Ausentes. }\end{array}$ \\
\hline 2005 & $\begin{array}{l}\text { Prado, J. } \\
\text { Freitas, C. A. } \\
\text { A. }\end{array}$ & $\begin{array}{l}\text { Rodriguésia } \\
\text { v. } 56, \text { n. } 86 \\
\text { p. } 98-102 \text {. }\end{array}$ & $\begin{array}{l}\text { Flora Da Reserva Ducke, Amazonas, Brasil: } \\
\text { Pteridophyta - Selaginellaceae } \\
\text { ^Ausentes. }\end{array}$ \\
\hline 2005 & $\begin{array}{l}\text { Prado, J. } \\
\text { Labiak, P. H. }\end{array}$ & $\begin{array}{l}\text { Rodriguésia } \\
\text { v. } 56, \text { n. } 86 \\
\text { p. } 98-102 .\end{array}$ & $\begin{array}{l}\text { Flora Da Reserva Ducke, Amazonas, Brasil: } \\
\text { Pteridophyta - Vittariaceae. } \\
{ }^{*} \text { Ausentes. }\end{array}$ \\
\hline 2005 & Prado, J. & $\begin{array}{l}\text { Rodriguésia } \\
\text { v. } 56, \text { n. } 86 \\
\text { p. } 29-32 \text {. }\end{array}$ & $\begin{array}{l}\text { Flora Da Reserva Ducke, Amazonas, Brasil: } \\
\text { Pteridophyta - Aspleniaceae. } \\
\text { ^Ausentes. }\end{array}$ \\
\hline 2005 & Prado, J. & $\begin{array}{l}\text { Rodriguésia } \\
\text { v. } 56, \text { n. } 86 \\
\text { p. } 33-34 \text {. }\end{array}$ & $\begin{array}{l}\text { Flora Da Reserva Ducke, Amazonas, Brasil: } \\
\text { Pteridophyta - Blechnaceae. } \\
{ }^{*} \text { Ausentes. }\end{array}$ \\
\hline 2005 & Prado, J. & $\begin{array}{l}\text { Rodriguésia } \\
\text { v. } 56, \text { n. } 86 \\
\text { p. } 38-42 \text {. }\end{array}$ & $\begin{array}{l}\text { Flora Da Reserva Ducke, Amazonas, Brasil: } \\
\text { Pteridophyta - Davalliacaea. } \\
\text { ^Ausentes. }\end{array}$ \\
\hline 2005 & Prado, J. & $\begin{array}{l}\text { Rodriguésia } \\
\text { v. } 56, \text { n. } 86 \\
\text { p. } 43-48 .\end{array}$ & $\begin{array}{l}\text { Flora Da Reserva Ducke, Amazonas, Brasil: } \\
\text { Pteridophyta - Dennstaedtiaceae. } \\
\text { “Ausentes. }\end{array}$ \\
\hline
\end{tabular}




\begin{tabular}{|c|c|c|c|}
\hline 2005 & Prado, J. & $\begin{array}{l}\text { Rodriguésia } \\
\text { v. } 56, \text { n. } 86 \\
\text { p. } 53-53 .\end{array}$ & $\begin{array}{l}\text { Flora Da Reserva Ducke, Amazonas, Brasil: } \\
\text { Pteridophyta - Gleicheniaceae. } \\
{ }^{*} \text { Ausentes. }\end{array}$ \\
\hline 2005 & Prado, J. & $\begin{array}{l}\text { Rodriguésia } \\
\text { v. } 56, \text { n. } 86 \\
\text { p. } 56-58 .\end{array}$ & $\begin{array}{l}\text { Flora Da Reserva Ducke, Amazonas, Brasil: } \\
\text { Pteridophyta - Grammitidacae. } \\
\text { ^Ausentes. }\end{array}$ \\
\hline 2005 & Prado, J. & $\begin{array}{l}\text { Rodriguésia } \\
\text { v. } 56, \text { n. } 86 \\
\text { p. } 59-66 \text {. }\end{array}$ & $\begin{array}{l}\text { Flora Da Reserva Ducke, Amazonas, Brasil: } \\
\text { Pteridophyta - Lomariopsidaceae. } \\
{ }^{*} \text { Ausentes. }\end{array}$ \\
\hline 2005 & Prado, J. & $\begin{array}{l}\text { Rodriguésia } \\
\text { v. } 56, \text { n. } 86 \\
\text { p. } 69-71 .\end{array}$ & $\begin{array}{l}\text { Flora Da Reserva Ducke, Amazonas, Brasil: } \\
\text { Pteridophyta - Marattiacae. } \\
{ }^{*} \text { Ausentes. }\end{array}$ \\
\hline 2005 & Prado, J. & $\begin{array}{l}\text { Rodriguésia } 15 \\
\text { v. } 56, \text { n. } 86 \\
\text { p. } 76-84 .\end{array}$ & $\begin{array}{l}\text { Flora Da Reserva Ducke, Amazonas, Brasil: } \\
\text { Pteridophyta - Polypodiacae. } \\
\text { *Ausentes. }\end{array}$ \\
\hline 2005 & Prado, J. & $\begin{array}{l}\text { Rodriguésia } \\
\text { v. } 56, \text { n. } 86 \\
\text { p. } 85-92 .\end{array}$ & $\begin{array}{l}\text { Flora Da Reserva Ducke, Amazonas, Brasil: } \\
\text { Pteridophyta - Pteridacae. } \\
{ }^{*} \text { Ausentes. }\end{array}$ \\
\hline 2005 & Prado, J. & $\begin{array}{l}\text { Rodriguésia } \\
\text { v. } 56, \text { n. } 86 \\
\text { p. } 93-97 .\end{array}$ & $\begin{array}{l}\text { Flora Da Reserva Ducke, Amazonas, Brasil: } \\
\text { Pteridophyta - Schizaeaceae } \\
{ }^{*} \text { Ausentes. }\end{array}$ \\
\hline 2005 & Prado, J. & $\begin{array}{l}\text { Rodriguésia } \\
\text { v. } 56, \text { n. } 86 \\
\text { p. } 103-104 .\end{array}$ & $\begin{array}{l}\text { Flora Da Reserva Ducke, Amazonas, Brasil: } \\
\text { Pteridophyta - Tectariaceae } \\
{ }^{*} \text { Ausentes. }\end{array}$ \\
\hline 2005 & Prado, J. & $\begin{array}{l}\text { Rodriguésia } \\
\text { v. } 56, \text { n. } 86 \text {. } \\
\text { p. } 105-107 .\end{array}$ & $\begin{array}{l}\text { Flora Da Reserva Ducke, Amazonas, Brasil: } \\
\text { Pteridophyta - Thelypteridacae. } \\
{ }^{*} \text { Ausentes. }\end{array}$ \\
\hline 2007 & $\begin{array}{l}\text { Zuquim, G. } \\
\text { Costa, F. R. C. } \\
\text { Prado, J. }\end{array}$ & $\begin{array}{l}\text { Biota neotropica } \\
\text { v.7, n. } 3 . \\
\text { p. } 217-233 \text {. }\end{array}$ & $\begin{array}{l}\text { Redução do esforço amostral vs. Retenção de } \\
\text { informação em inventários de pteridófitas na } \\
\text { Amazônia Central. } \\
{ }^{*} \text { Comunidade; gradiente ambiental; floresta tropical; } \\
\text { protocolo de amostragem, riqueza de espécies, } \\
\text { samambaia, textura do solo. }\end{array}$ \\
\hline 2015 & $\begin{array}{l}\text { Sampaio, A. F; } \\
\text { Souza, M. G. } \\
\text { C. Pietrobom. } \\
\text { M.R. }\end{array}$ & $\begin{array}{l}\text { Acta Biológica } \\
\text { Catarinense. } \\
\text { v. } 2 \text {, n. } 1 . \\
\text { p. } 55-69\end{array}$ & $\begin{array}{l}\text { Samambaias da Província Petrolífera de Urucu, Coari, } \\
\text { Amazonas, Brasil: Cyatheaceae, Gleicheniaceae, } \\
\text { Lygodiaceae, Schizaeaceae, Marattiaceae e } \\
\text { Metaxyaceae. } \\
\text { *Inventário; plantas vasculares; plantas sem sementes }\end{array}$ \\
\hline
\end{tabular}

Fonte: autores (2017).

Em relação ao estado do Pará (Quadro 5), os dados obtidos indicaram que, no período analisado, as publicações cientificas sob a forma de artigo científico, somaram 40 (60,6\%). Em comparação com o número de publicações para o mesmo período, no estado do Amazonas, verificou-se um incremento igual a $25,7 \%$.

QUADRO 5 - Ano da publicação, autor (a) res (as), periódicos, título e palavras - chave, dos artigos e Notas Científicas publicados entre 1992 a 2017. Estado do Pará

\begin{tabular}{|c|l|l|l|}
\hline Ano & \multicolumn{1}{|c|}{ Autores } & Periódicos/Dados & \multicolumn{1}{|c|}{ Títulos + palavras-chave* } \\
\hline 1996 & Silva, M.F.F.; & Acta Amazonica & Aspectos ecológicos da vegetação \\
& Secco, R. S; & v.26. n.1/2, p. 17- & $\begin{array}{l}\text { rupestre da Serra dos Carajás, } \\
\text { Estado do Pará, Brasil }\end{array}$ \\
\hline \multirow{3}{*}{2004} & Lobo, M.G. & R4. & Composição florística e abundância \\
& Almeida, S. S. T. & Acta amazônica & $\begin{array}{l}\text { de pteridófitas em três ambientes da } \\
\text { bacia do rio Guamá, Belém, Pará, }\end{array}$ \\
& Andrade, L. H. C & v.34, n. 1 & Brasil \\
& Barros, I. C. & p. 35-42. & *Amazônia Brasileira, abundância e \\
& 3Van Den Berg, & & composição florística de pteridófitas \\
& M.L. & & \multicolumn{2}{|c}{} \\
\hline
\end{tabular}




\begin{tabular}{|c|c|c|c|}
\hline 2006 & $\begin{array}{l}\text { Costa, J. M; } \\
\text { Souza, M. G. C. } \\
\text { Pietrobom, M. R. }\end{array}$ & $\begin{array}{l}\text { Rev. Biol. Neotrop. } \\
\text { v. } 3, \text { n. } 1 \\
\text { p. } 4-12\end{array}$ & $\begin{array}{l}\text { Levantamento Florístico Das } \\
\text { Pteridófitas (Lycophyta E } \\
\text { Monilophyta) Do Parque Ambiental } \\
\text { De Belém (Belém, Pará, Brasil). } \\
\text { `Florística; Pará; Parque Ambiental } \\
\text { de Belém; Pteridófitas; Região } \\
\text { Amazônica. }\end{array}$ \\
\hline 2007 & $\begin{array}{l}\text { Costa. J. M. } \\
\text { Pietrobom. M. R. }\end{array}$ & $\begin{array}{l}\text { BMP Emilio Goeldi } \\
- \text { CN. } \\
\text { v. } 2, \text { n. } 3 \\
\text { p. } 45-55\end{array}$ & $\begin{array}{l}\text { Pteridófitas (Lycophyta e } \\
\text { Monilophyta) da llha de Mosqueiro, } \\
\text { município de Belém, estado do Pará, } \\
\text { Brasil } \\
\text { *Florística. Samambaias e plantas } \\
\text { afins. Ilha de Mosqueiro. }\end{array}$ \\
\hline 2007 & $\begin{array}{l}\text { Maciel, S. } \\
\text { Souza, M. G. C. } \\
\text { Pietrobom. M. R }\end{array}$ & $\begin{array}{l}\text { BMP Emílio } \\
\text { Goeldi. - CN } \\
\text { v. } 2, \text { n. } 2 \\
\text { p. } 69-83\end{array}$ & $\begin{array}{l}\text { Licófitas e monilófitas do Bosque } \\
\text { Rodrigues Alves Jardim Botânico da } \\
\text { Amazônia, município de Belém, } \\
\text { estado do Pará, Brasil. } \\
\text { *Licófitas. Monilófitas. Jardim } \\
\text { Botânico. Floresta Amazônica. Pará. } \\
\text { Pteridófitas }\end{array}$ \\
\hline 2008 & $\begin{array}{l}\text { Silva, M. R. P. } \\
\text { Rosário*, S. M. }\end{array}$ & $\begin{array}{l}\text { BMP Emílio Goeldi } \\
- \text { CN } \\
\text { v. } 3, \text { n.2 } \\
\text { p. } 151-163 .\end{array}$ & $\begin{array}{l}\text { Licófitas e monilófitas (Pteridophyta) } \\
\text { da Floresta Nacional de Caxiuanã, } \\
\text { estado do Pará, Brasil: chave para } \\
\text { as famílias e as espécies de } \\
\text { Aspleniaceae e Blechnaceae } \\
\text { `Taxonomia. Aspleniaceae. } \\
\text { Blechnaceae. Pteridófitas. Floresta } \\
\text { Amazônica. }\end{array}$ \\
\hline 2009 & $\begin{array}{l}\text { Pietrobom. M. R. } \\
\text { Maciel, S. } \\
\text { Costa, J. M. } \\
\text { Souza, M. G. C. } \\
\text { Trindade, M. J. } \\
\text { Fonseca, M.S. S }\end{array}$ & $\begin{array}{l}\text { BMP Emílio } \\
\text { Goeldi- CN } \\
\text { v. } 4, \text { n. } 1 \\
\text { p. } 37-45 .\end{array}$ & $\begin{array}{l}\text { Licófitas ocorrentes na Floresta } \\
\text { Nacional de Caxiuanã, estado do } \\
\text { Pará, Brasil: Lycopodiaceae e } \\
\text { Selaginellaceae. } \\
\text { *Selaginella. Huperzia. Lycopodiella. } \\
\text { Lycophyta. }\end{array}$ \\
\hline 2010 & $\begin{array}{l}\text { Costa. J. M. } \\
\text { Pietrobom. M. R }\end{array}$ & $\begin{array}{l}\text { Rodriguésia } \\
\text { v. } 61, \text { n. } 2 \\
\text { p. } 223-232\end{array}$ & $\begin{array}{l}\text { Samambaias e licófitas do Parque } \\
\text { Ecológico do Parque Ecológico do } \\
\text { Gunma, município de Santa Bárbara } \\
\text { do Pará, Brasil. } \\
\text { *Amazônia brasileira, florística, } \\
\text { plantas vasculares sem sementes. }\end{array}$ \\
\hline 2010 & $\begin{array}{l}\text { Maciel, S. } \\
\text { Pietrobom, M. R }\end{array}$ & $\begin{array}{l}\text { Rodriguésia } \\
\text { v. } 61, \text { n. } 3 \\
\text { p. } 405-414\end{array}$ & $\begin{array}{l}\text { Dryopteridaceae e } \\
\text { Lomariopsidaceae (Polypodiopsida) } \\
\text { do Campo Experimental da Embrapa } \\
\text { Amazônia Oriental, Moju, Pará, } \\
\text { Brasil } \\
\text { ^Amazônia brasileira, } \\
\text { Elaphoglossum, Nephrolepis, } \\
\text { samambaias. } \\
\end{array}$ \\
\hline 2010 & $\begin{array}{l}\text { Maciel. S. } \\
\text { Pietrobom. M. R. }\end{array}$ & $\begin{array}{l}\text { Acta bot. bras. } \\
\text { v. } 24, \text { n. } 1 \\
\text { p. } 8-19\end{array}$ & $\begin{array}{l}\text { Pteridaceae (Polypodiopsida) do } \\
\text { Campo Experimental da Embrapa } \\
\text { Amazônia Oriental, município de } \\
\text { Moju, estado do Pará, Brasil. } \\
\text { Amazônia, flora, samambaias, } \\
\text { taxonomia }\end{array}$ \\
\hline 2010 & Silvestre, L.S. & $\begin{array}{l}\text { Rodriguésia } \\
\text { v. } 61, \mathrm{n}, 1 . \\
\text { p. } 109-114\end{array}$ & $\begin{array}{l}\text { Notas nomenclaturais em } \\
\text { Aspleniaceae (Polypodiopsida) } \\
\text { ocorrentes no Brasil. } \\
\text { `Asplenium, Neotrópico, } \\
\text { samambaias, taxonomia, tipificação. }\end{array}$ \\
\hline
\end{tabular}




\begin{tabular}{|c|c|c|c|}
\hline 2012 & $\begin{array}{l}\text { Goés -Neto, I. A. } \\
\text { Pietrobom, M. R. }\end{array}$ & $\begin{array}{l}\text { Acta bot. bras. } \\
\text { v. } 26, \text { n. } 2 \text {. } \\
\text { p. } 456-463 .\end{array}$ & $\begin{array}{l}\text { Aspleniaceae (Polypodiopsida) do } \\
\text { Corredor de Biodiversidade do Norte } \\
\text { do Pará, Brasil: um fragmento do } \\
\text { Centro de Endemismo Guiana } \\
\text { *Asplenium, taxonomia, florística, } \\
\text { Floresta Amazônica, Escudo Guiana. }\end{array}$ \\
\hline 2012 & $\begin{array}{l}\text { Goés-Neto, L. A. } \\
\text { A. Pietrobom, M. } \\
\text { R. }\end{array}$ & $\begin{array}{l}\text { Rodriguésia } \\
\text { v. } 63, \text { n. } 4, \text { p. } \\
1151-1155 \\
\text { Nota Científica }\end{array}$ & $\begin{array}{l}\text { Novos registros de samambaias para } \\
\text { a Amazônia Brasileira } \\
\text { *filicíneas, Centro de Endemismo } \\
\text { Guiana, Pará, Brasil. }\end{array}$ \\
\hline 2014 & $\begin{array}{l}\text { Goés-Neto, L. A. } \\
\text { Pietrobom, M. R. }\end{array}$ & $\begin{array}{l}\text { Hoehnea } \\
\text { v. } 41, \text { n. } 3 . \\
\text { p. } 401-409\end{array}$ & $\begin{array}{l}\text { Cyatheales (Polypodiopsida) do } \\
\text { Corredor de Biodiversidade do Norte } \\
\text { do Pará, Brasil. } \\
\text { Amazonia, Cyatheaceae, Guiana } \\
\text { Endemism Center, Metaxyaceae }\end{array}$ \\
\hline 2014 & $\begin{array}{l}\text { Medeiros, P. S. } \\
\text { Ferreira, L.V. } \\
\text { Costa, A. C. L. }\end{array}$ & $\begin{array}{l}\text { BMP Emílio } \\
\text { Goeldi - CN } \\
\text { v. } 9, \text { n. } 1 \\
\text { p. } 223-230\end{array}$ & $\begin{array}{l}\text { O impacto do estresse hídrico } \\
\text { artificial na comunidade de } \\
\text { samambaias e licófitas em um sub- } \\
\text { bosque de floresta ombrófila na } \\
\text { Amazônia oriental } \\
\text { ^Amazônia. Pteridófitas. El Niño. } \\
\text { Mudanças climáticas. }\end{array}$ \\
\hline 2014 & $\begin{array}{l}\text { Travassos, C. C. } \\
\text { Jardim, M. A. G. } \\
\text { Maciel, S. }\end{array}$ & $\begin{array}{l}\text { Biota Amazônia } \\
\text { v. } 4, \text { n. } 4 \text {. } \\
\text { p. } 40-44\end{array}$ & $\begin{array}{l}\text { Florística e ecologia de samambaias } \\
\text { e licófitas como indicadores de } \\
\text { conservação ambiental. } \\
\text { *epífitas, parque urbano, } \\
\text { ecossistemas amazônicos. }\end{array}$ \\
\hline 2015 & $\begin{array}{l}\text { Goés Neto, L. A. } \\
\text { Maciel, S. } \\
\text { Pietrobom, M. R. } \\
\text { Valdespino. I. A. }\end{array}$ & $\begin{array}{l}\text { Rodriguésia } \\
\text { v. } 66, \text { n.1. } \\
\text { p. } 229-244\end{array}$ & $\begin{array}{l}\text { Licófitas (Lycopodiophyta) do } \\
\text { Corredor de Biodiversidade do Norte } \\
\text { do Pará, Brasil } \\
\text { *Amazônia, Centro de Endemismo } \\
\text { Guiana, Lycopodiaceae, Selaginella. }\end{array}$ \\
\hline 2015 & $\begin{array}{l}\text { Goés-Neto, L. A. } \\
\text { A.; Pietrobom, } \\
\text { M.R.; Maciel.S. }\end{array}$ & $\begin{array}{l}\text { Pesquisas, } \\
\text { Botânica. } \\
\text { v.65, p. 245-256 }\end{array}$ & $\begin{array}{l}\text { Schizaeales (Polypodiopsida) Do } \\
\text { Corredor de Biodiversidade do Norte } \\
\text { do Pará, Brasil. } \\
{ }^{*} \text { Samambaia, Amazônia, Taxonomia }\end{array}$ \\
\hline 2015 & $\begin{array}{l}\text { Miranda. C. } \\
\text { Ilkiu-Borges. A. L. } \\
\text { Maciel. S. }\end{array}$ & $\begin{array}{l}\text { Biota Amazônia } \\
\text { v. } 5, n, 2 . \\
\text { p. } 26-30\end{array}$ & $\begin{array}{l}\text { Avencas (Adiantum L. - Pteridaceae) } \\
\text { do município de Acará, Pará, Brasil. } \\
\text { *samambaias, taxonomia, Amazônia } \\
\text { brasileira }\end{array}$ \\
\hline 2015 & $\begin{array}{l}\text { Pietrobom. M. R. } \\
\text { Medeiro, P. S } \\
\text { Fonseca, M. S. } \\
\text { Maciel, S; Souza, } \\
\text { M. G. C.; Costa, J. } \\
\text { M. }\end{array}$ & $\begin{array}{l}\text { Pesquisas, } \\
\text { botânica } \\
\text { n.68, p. } 349- \\
361\end{array}$ & $\begin{array}{l}\text { Contribuição à Preservação Da } \\
\text { Floresta Nacional De Caxiuanã, Pará, } \\
\text { Brasil: Licófitas E Samambaias. } \\
\text { `Seedless vascular plants, } \\
\text { Conservation, Brazilian Amazon. }\end{array}$ \\
\hline 2015 & $\begin{array}{l}\text { Teixeira. G. } \\
\text { Maciel, S. } \\
\text { Pietrobom. M. R }\end{array}$ & $\begin{array}{l}\text { Biota Amazônia } \\
\text { v. } 5, \text { n. } 1 \\
\text { p. } 68-73\end{array}$ & $\begin{array}{l}\text { Potencial utilitário de licófitas e } \\
\text { samambaias: aplicabilidade ao } \\
\text { contexto amazônico. } \\
\text { *Amazônia, Pará, samambaias, usos, } \\
\text { medicinal }\end{array}$ \\
\hline 2015 & $\begin{array}{l}\text { Teixeira, } \\
\text { Pietrobom, M. R. }\end{array}$ & $\begin{array}{l}\text { Rodriguésia } \\
\text { v. } 66, \text { n.3 } \\
\text { p. } 807-827\end{array}$ & $\begin{array}{l}\text { Hymenophyllaceae (Polypodiopsida) } \\
\text { na Mesorregião Metropolitana de } \\
\text { Belém, Estado do Pará, Brasil } \\
\text { ^Amazônia brasileira, samambaias, } \\
\text { Didymoglossum, Trichomanes. }\end{array}$ \\
\hline
\end{tabular}




\begin{tabular}{|c|c|c|c|}
\hline 2016 & $\begin{array}{l}\text { Goés-Neto. L. A. } \\
\text { Pallos, J.; Salino, } \\
\text { A. }\end{array}$ & $\begin{array}{l}\text { Rodriguésia } \\
\text { v. } 67, \text { n. } 5 . \\
\text { p. } 1177-1180 \\
\end{array}$ & $\begin{array}{l}\text { Flora das cangas da Serra dos } \\
\text { Carajás, Pará, Brasil: Selaginellaceae } \\
\text { *Amazônia, licófitas, rocha } \\
\text { ferruginosa, Selaginella, taxonomia }\end{array}$ \\
\hline 2016 & Maciel, S. & $\begin{array}{l}\text { Rodriguésia } \\
\text { v. } 67, \text { n. } 1 . \\
\text { p. } 077-084\end{array}$ & $\begin{array}{l}\text { Nephrolepis (Lomariopsidaceae - } \\
\text { Polypodiopsida) na Amazônia } \\
\text { brasileira } \\
\text { *samambaias, flora, taxonomia, } \\
\text { floresta amazônica. }\end{array}$ \\
\hline 2016 & $\begin{array}{l}\text { Moura, I. O. } \\
\text { Arruda. A; J. } \\
\text { Salino, A. }\end{array}$ & $\begin{array}{l}\text { Rodriguésia } \\
\text { v. } 67, \text { n. } 5 \text {, } \\
\text { p. } 1141-1144\end{array}$ & $\begin{array}{l}\text { Flora das cangas da Serra dos } \\
\text { Carajás, Pará, Brasil: Aspleniaceae } \\
\text { *Amazônia, Asplenium, flora, } \\
\text { samambaias, taxonomia. }\end{array}$ \\
\hline 2016 & $\begin{array}{l}\text { Moura, I. O. } \\
\text { Salino, A. }\end{array}$ & $\begin{array}{l}\text { Rodriguésia } \\
\text { v. } 67, \text { n.5, p. } \\
1151-1157\end{array}$ & $\begin{array}{l}\text { Flora das cangas da Serra dos } \\
\text { Carajás, Pará, Brasil: } \\
\text { Dryopteridaceae } \\
\text { `Amazônia, Ctenitis, Dryopteris, } \\
\text { Elaphoglossum, Polybotrya, } \\
\text { samambaias. }\end{array}$ \\
\hline 2016 & $\begin{array}{l}\text { Moura, I. O. } \\
\text { Salino, A. }\end{array}$ & $\begin{array}{l}\text { Rodriguésia } \\
\text { v. } 67, \text { n.5, } \\
\text { p. } 1167-1175\end{array}$ & $\begin{array}{l}\text { Flora das cangas da Serra dos } \\
\text { Carajás, Pará, Brasil: Pteridaceae } \\
\text { *Amazônia, flora, samambaias, } \\
\text { taxonomia. }\end{array}$ \\
\hline 2016 & $\begin{array}{l}\text { Pallos, J. } \\
\text { Goés-Neto, L. A. } \\
\text { A. } \\
\text { Costa, J. M. } \\
\text { Souza. F. S. } \\
\text { Pietrobom, M. R. }\end{array}$ & $\begin{array}{l}\text { Rodriguésia } \\
\text { v. } 67, \text { n. } 4, \text { p. } 997 \\
-1009 .\end{array}$ & $\begin{array}{l}\text { Licófitas e samambaias da Serra do } \\
\text { Itauajuri, município de Monte Alegre, } \\
\text { Pará, Brasil } \\
\text { `Amazônia brasileira, florística, } \\
\text { formações campestres, mata ripária, } \\
\text { pteridófitas. }\end{array}$ \\
\hline 2016 & $\begin{array}{l}\text { Salino. A. } \\
\text { Arruda, A. J. }\end{array}$ & $\begin{array}{l}\text { Rodriguésia } \\
\text { v.67, n. } 5, \text { p. } \\
1145-1147\end{array}$ & $\begin{array}{l}\text { Flora das cangas da Serra dos } \\
\text { Carajás, Pará, Brasil: Cyatheaceae } \\
\text { ×Amazônia, Cyathea, flora, } \\
\text { samambaias, taxonomia }\end{array}$ \\
\hline 2016 & $\begin{array}{l}\text { Salino. A. } \\
\text { Arruda, A. J. }\end{array}$ & $\begin{array}{l}\text { Rodriguésia } \\
\text { v.67, n. 5, p. } \\
1149-1150\end{array}$ & $\begin{array}{l}\text { Flora das cangas da Serra dos } \\
\text { Carajás, Pará, Brasil: } \\
\text { Dennstaedtiaceae } \\
\text { * Amazônia, flora, Pteridium, } \\
\text { samambaias, taxonomia }\end{array}$ \\
\hline 2016 & $\begin{array}{l}\text { Salino. A. } \\
\text { Arruda, A. J. }\end{array}$ & $\begin{array}{l}\text { Rodriguésia } \\
\text { v.67, n. } 5, \mathrm{p} \text {. } \\
1159-1161\end{array}$ & $\begin{array}{l}\text { Flora das cangas da Serra dos } \\
\text { Carajás, Pará, Brasil: Lycopodiaceae } \\
\text { *Amazônia, flora, Licófitas, } \\
\text { Palhinhaea, taxonomia. }\end{array}$ \\
\hline 2016 & $\begin{array}{l}\text { Salino. A. } \\
\text { Arruda, A. J. }\end{array}$ & $\begin{array}{l}\text { Rodriguésia } \\
\text { v.67, n. } 5, \mathrm{p} \text {. } \\
1163-1164\end{array}$ & $\begin{array}{l}\text { Flora das cangas da Serra dos } \\
\text { Carajás, Pará, Brasil: Lygodiaceae } \\
\text { *Amazônia, flora, Lygodium, } \\
\text { Samambaias, taxonomia. }\end{array}$ \\
\hline 2016 & $\begin{array}{l}\text { Salino. A. } \\
\text { Arruda, A. J. }\end{array}$ & $\begin{array}{l}\text { Rodriguésia } \\
\text { v.67, n. } 5, \mathrm{p} . \\
1164-1165\end{array}$ & $\begin{array}{l}\text { Flora das cangas da Serra dos } \\
\text { Carajás, Pará, Brasil: Oleandraceae } \\
\text { * Amazônia, flora, Oleandra, } \\
\text { samambaias, taxonomia }\end{array}$ \\
\hline 2017 & $\begin{array}{l}\text { Almeida, T. E. } \\
\text { Souza, D. C. S. } \\
\text { Costa, E. C. } \\
\text { Salino, A. }\end{array}$ & $\begin{array}{l}\text { Rodriguésia } \\
\text { v. } 68, \text { n. } 3, \text { p. } 871 \\
-880\end{array}$ & $\begin{array}{l}\text { Flora das cangas da Serra dos } \\
\text { Carajás, Pará, Brasil: Polypodiaceae } \\
\text { `Campyloneurum, FLONA Carajás, } \\
\text { Microgramma, samambaias, } \\
\text { taxonomia }\end{array}$ \\
\hline 2017 & Almeida, T. E. & $\begin{array}{l}\text { Rodriguésia } \\
\text { v. } 68, \text { n. } 3, \text { p. } 881\end{array}$ & $\begin{array}{l}\text { Flora das cangas da Serra dos } \\
\text { Carajás, Pará, Brasil: Schizaeaceae. } \\
\text { ^Actinostachys, FLONA Carajás, }\end{array}$ \\
\hline
\end{tabular}




\begin{tabular}{|l|l|l|l|}
\hline 2017 & -882 & samambaias, Schizaea, taxonomia. \\
\hline 2017 & $\begin{array}{l}\text { Pallos, J. } \\
\text { Goés-Neto, L. A. } \\
\text { A. Salino, A. }\end{array}$ & $\begin{array}{l}\text { Rodriguésia } \\
\text { v. 68, n. 3, p. 847 } \\
\text { Pallos, J. } \\
\text { Goés-Neto, L. A. } \\
\text { A. } \\
\text { Salino, A. }\end{array}$ & $\begin{array}{l}\text { Rodriguésia } \\
\text { v. 68, n. 3, p. 859 } \\
\text { Carajás, Pará, Brasil: } \\
\text { Hymenophyllaceae } \\
\text { *Amazônia, rocha ferruginosa, } \\
\text { samambaias, Trichomanes, } \\
\text { Vandenboschia. }\end{array}$ \\
\hline $\begin{array}{l}\text { Salino, A. } \\
\text { Arruda, A. J. } \\
\text { Dittrich, A. O. }\end{array}$ & $\begin{array}{l}\text { Flora das cangas da Serra dos } \\
\text { Carajás, Pará, Brasil: Lindsaeaceae } \\
\text { *Amazônia, Lindsaea, rocha } \\
\text { ferruginosa, samambaias, taxonomia. }\end{array}$ \\
& $\begin{array}{l}\text { Rodriguésia } \\
\text { v. 68, n. 2, p. 833 } \\
-841 .\end{array}$ & $\begin{array}{l}\text { Flora das cangas da Serra dos } \\
\text { Carajás, Pará, Brasil: Blechnaceae } \\
\text { Flora of the cangas of Serra dos } \\
\text { Carajás, Pará, Brazil: Blechnaceae } \\
\text { *Amazônia, Blechnum, } \\
\text { Neoblechnum, samambaias, } \\
\text { taxonomia, Telmatoblechnum }\end{array}$ \\
\hline 2017 & $\begin{array}{l}\text { Viveiros, R. S. } \\
\text { Salino, A. }\end{array}$ & $\begin{array}{l}\text { Rodriguésia } \\
\text { v. 68, n. 3, p. 883 } \\
-886 .\end{array}$ & $\begin{array}{l}\text { Flora das cangas da Serra dos } \\
\text { Carajás, Pará, Brasil: Tectariaceae } \\
\text { *Amazônia, flora, samambaias, } \\
\text { Tectaria, Triplophyllum. }\end{array}$ \\
\hline
\end{tabular}

Fonte: autores (2018)

A análise dos dados obtidos quanto a qualificação. Capes (QualisCapes), dos 66 artigos selecionados, indicou que 51 (77,3\%), apresentam Qualis B1 (Figura 2), o que determina uma busca pelos pesquisadores por periódicos com maior relevância em função do número de leitores e citações.

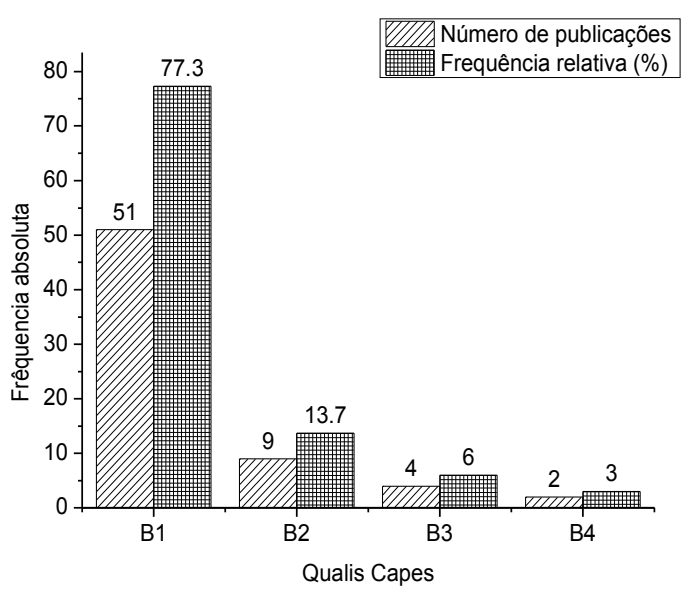

FIGURA 2 - Número de publicações e o QualisCapes dos sessenta e seis artigos selecionados.

Fonte: autores (2018)

Em estudo efetuado por Figueiredo Filho et al. (2014), os autores concluiram que quanto mais elevado for o Qualis, subtende-se que tanto melhor será a publicação, ou no mínimo, maior o grau de exigência e concorrência para que esse artigo seja submetido. Nessa revisão, notou-se que a maior concentração de artigos científicos, foram publicados em periódicos com Qualis B1, o que incrementa a análise da mesma, quanto a evolução das pesquisas Pteridophyta e a contribuição das mesmas para a conservação desse vegetal. 
Quanto a aplicação dos indicadores bibliométricos, a análise dos dados obtidos indicou que, os 66 artigos selecionados não mostraram similaridade entre nenhum, o que já era esperado e concatena com o resultado anteriormente obtido (Tabela 6).

TABELA 6 - Dados bibliométricos obtidos nos sessenta e seis artigos selecionados.

\begin{tabular}{lc}
\hline Dados bibliométricos & Frequência \\
\hline Publicações & 66 \\
Fontes de publicações & 02 \\
Autores & 50 \\
Instituições & 13 \\
Palavras-chave & 262 \\
\hline
\end{tabular}

Fonte: autores (2018).

Em estudo sobre o uso da bibliometria, Santos et al. (2016), afirmaram que a bibliometria tem sido utilizada como um método de análise quantitativa para pesquisa científica. Os dados estatísticos elaborados por meio dos estudos bibliométricos mensuram a contribuição do conhecimento científico derivado das publicações em determinadas áreas. Esses dados podem ser utilizados na representação das atuais tendências de pesquisa e na identificação de temas para novas pesquisas. Em face desse argumento, os dados obtidos para essa pesquisa, permitem tal mensuração com a aplicação da estatística descritiva.

Em relação as pesquisas realizadas nos estados do Amazonas e Pará, a análise também indicou que $103(59,19 \%)$ dessas pesquisas não foram realizadas nos estados do Amazonas ou Pará. Os outros cinco $(2,87 \%)$ foram pesquisas realizadas nesses estados, porém, o tema central, não foram as pteridófitas (Ex.: Bryophyta; Mauritia flexuosa Lin. Fil.; Sapotaceae, etc.). Com isso, o descritor geográfico tornou-se a principal ferramenta para a seleção efetiva dos artigos científicos, cujos temas fossem similares ao desta pesquisa.

Os dados analisados quanto a identificação e indexação dos 66 artigos científicos selecionados, indicaram que isso ocorreu com lista gerada com 252 palavras-chave, dentre estas, destacaram-se: família $(\bar{x}=8,23$; gênero = pteridófitas $=\bar{x}=5,76)$. Isso reforça a escolha destas palavras para a composição dos descritores.

A pesquisa realizada por Medeiros et al. (2015), em Florianópolis - SC, acerca da aplicação de revisão sistemática e análise bibliométria, indicou que a pesquisa cientifica deve se valer de suportes confiáveis em termos de referências, uma vez que fornece ao pesquisador uma matéria-prima criteriosamente selecionada. Ambas as ferramentas, revisão sistemática e análise bibliométria, foram utilizadas nesta pesquisa, por isso, a média de descarte obteve valor elevado, ou seja, $108(62 \%)$.

Quanto aos 13 periódicos selecionados, apenas 10 publicaram artigos com, pelo menos, dois descritores utilizados. Por isso, três (Biotemas; Revista Brasileira de Biociências e Revista Brasileira de Botânica), não eram artigos para a seleção final, com isso, analisaram-se os 66 artigos dos 10 periódicos restantes.

No relato científico produzido por Vanz e Stumpf (2010), essas autoras indicaram que se deve ordenar por áreas de publicação, biologia, biociências na área I; engenharia, na área II. Nesse sentido, verificou-se que, como UC's envolvem a área da engenharia ambiental, $e$ as pteridófitas são utilizadas como bioindicadoras, o corte efetuado não afetou o cerne dessa pesquisa, pois os artigos selecionados contemplam tais áreas, que se relacionam de forma direta com esta ENCICLOPÉDIA BIOSFERA, Centro Científico Conhecer - Goiânia, v.15 n.27; p.65 2018 
pesquisa. Após a análise estatística desses dados, esta indicou que, em média, houveram sete publicações selecionadas para cada periódico após a aplicação dos descritores (Tabela 7).

TABELA 7 - Valores para mínimo, máximo, média e desvio padrão em função dos periódicos selecionados.

\begin{tabular}{lcc}
\hline & DADOS & VALORES \\
\hline Tamanho da amostra & 10 \\
Mínimo & 1,0 \\
Máximo & 44 \\
Média & 6,9 \\
Desvio Padrão & 14,0 \\
\hline
\end{tabular}

Fonte: autores (2018)

Os dados indicaram também que o número de artigos amostrados, por periódico, sofre distribuição irregular (desvio padrão $=14$ ), ou seja, afastam-se da média $(6,9)$. Isso indica que há periódicos com maior número de publicações, e viceversa. Com isso, os resultados das pesquisas não serão acessados não ser acessados pela comunidade acadêmica e órgãos elaboradores de políticas públicas sobre conservação da diversidade biológica e outras linhas de conservação ambiental. No caso dessa pesquisa, as pteridófitas, logo, ainda é passiva de sofrer perdas endêmicas. Quanto aos 57 pesquisadores, a análise dos dados indicou que, deste grupo, sete $(12,28 \%)$ foram mais prolíferos em pesquisas e publicações sobre samambaias e licófitas, ou seja, pteridófitas nos dois estados estudados (Tabela 8).

TABELA 8 - Valores para frequência absoluta, frequência relativa e média das publicações de pesquisadores sobre samambaias e licófitas no Amazonas e Pará, em relação aos sessenta e seis artigos selecionados.

\begin{tabular}{llcc}
\hline \multicolumn{1}{c}{ Pesquisadores } & fi & frp (\%) & $\overline{\boldsymbol{x}}$ \\
\hline Alexandre Salino & 13 & 19,69 & 0,22 \\
André Jardim Arruda & 05 & 7,57 & 0,08 \\
Carlos A. A. de Freitas & 05 & 7,57 & 0,08 \\
Jefferson Prado & 21 & 31,81 & 0,36 \\
Luís Armando A. Goés-Neto & 06 & 9,09 & 0,10 \\
Marcio Roberto Pietrobom & 16 & 24,24 & 0,28 \\
Maria Gorete C. Souza & 05 & 7,57 & 0,08 \\
Sebastião Maciel & 13 & 19,69 & 0,22 \\
\hline
\end{tabular}

Legendas: $f i$ - frequência absoluta; frp - frequência relativa porcentual; $\bar{x}=$ média aritmética. Fonte: autores (2018)

A análise desses dados indicou que quatro pesquisadores produziram mais artigos em parcerias do que isoladamente. Nesse contexto, o mais prolífero (Jefferson Prado), que está vinculado ao Instituto de Botânica de São Paulo, de acordo com os artigos analisados e averiguação em notas de rodapé. Outros dois (Marcio Roberto Pietrobom e Sebastião Maciel), são vinculados ao Museu Paraense Emílio Goeldi - Coordenação de Botânica. O outro (Alexandre Salino), está vinculado a Universidade Federal de Minas Gerais - UFMG.

$\mathrm{Na}$ pesquisa realizada por Pietrobom et al. (2015), os autores relataram que a composição de representatividade especifica de plantas vasculares sem sementes ainda é pouco conhecida na região, gerando uma lacuna nas informações sobre o grupo, o que dificulta o entendimento da biogeografia e ecologia destes vegetais neste bioma. Os dados ora obtidos indicam que essa escassez é profunda, isso porque o valor da média obtida pelos quatro pesquisadores mais prolíferos, em 27 anos, não atingiu valor elevado. 
A análise efetuada a partir da estatística descritiva (Tabela 9), indicou que a dispersão das 68 publicações tanto como autores ou coautores, está próxima da média, e isso significa que os dados das pesquisas estão acessíveis a quem deles quiser dispor. Com isso, há uma intercomunicação e troca de informações mais rápidas, o que favorece a elaboração de medidas de conservação das pteridófitas.

TABELA 9 - Valores para mínimo, máximo, média e desvio padrão quanto as publicações dos pesquisadores mais prolíferos nos sessenta e seis artigos selecionados.

\begin{tabular}{l|c}
\hline \multicolumn{1}{c|}{ Dados } & Valores obtidos \\
\hline Tamanho da amostra & 8 \\
\hline Mínimo & 3 \\
\hline Máximo & 21 \\
\hline Média & 9,3 \\
\hline Desvio Padrão & 6,6 \\
\hline Fonte: autores (2018)
\end{tabular}

Os dados obtidos e analisados indicaram que as instituições envolvidas com pesquisas sobre pteridófitas nos estados do Amazonas e Pará indicaram que estas são 16 no total, sendo $15(3,75 \%)$ são nacionais (Empresa Brasileira de Pesquisa Agropecuária EMBRAPA; Conselho Nacional de Desenvolvimento Científico e Tecnológico - CNPQ; Instituto de Botânica de São Paulo - IBSP; Instituto Federal do Pará - IFPA; Universidade Federal de Pernambuco - UFPE; Instituto de Pesquisas da Amazônia INPA; Museu Paraense Emilio Goeldi - MPEG; Secretaria Executiva de Educação - SEE; Universidade Federal de Juiz de Fora - UFJF; Universidade Federal de Minas Gerais - UFMG; Universidade Federal do Oeste do Pará - UFOPA; Universidade Federal do Pará; Universidade Federal de Pernambuco - UFPE; Universidade Federal do Paraná - UFPR; Universidade Federal Rural da Amazônia - UFRA, e Universidade do Vale dos Sinos UNISINOS),e uma (6.25\%) é internacional (Universidad do Panamá)., e que produziram pesquisas com resultados publicados nos 10 periódicos. A análise dos dados indicou também que estas realizaram tais ações, de forma isolada ou em parcerias (Tabela 10).

TABELA 10 - Valores para frequência a absoluta, absoluta acumulada, frequência relativa e relativa acumulada além da média para as pesquisas desenvolvidas pelas instituições sobre pteridófitas.

\begin{tabular}{|c|c|c|c|c|c|}
\hline \multirow[t]{2}{*}{ INSTITUIÇÕES } & \multicolumn{5}{|c|}{ VALORES } \\
\hline & fi & $f i_{\mathrm{acm}}$ & $\operatorname{frp}(\%)$ & $f r p_{\mathrm{acm}}$ & $\bar{X}$ \\
\hline CNPQ; MPEG & 1 & ---- & 2,86 & ---- & 0,02 \\
\hline EMBRAPA; MPEG; UFPE & 1 & 2 & 2,86 & 5,72 & 0,02 \\
\hline IBSP: INPA & 2 & 4 & 5,70 & 11,42 & 0,05 \\
\hline & fi & $f i_{a c m}$ & frp (\%) & $f r p_{\mathrm{acm}}$ & $\bar{X}$ \\
\hline IBSP; UFPR & 1 & 5 & 2,86 & 14,29 & 0,02 \\
\hline IFPA; UFPA & 1 & 6 & 2,86 & 17,14 & 0,02 \\
\hline INPA; IBSP & 6 & 12 & 17,14 & 34,28 & 0,17 \\
\hline INPA; UNISINOS & 1 & 13 & 2,86 & 37,13 & 0,02 \\
\hline MPEG; SEE & 2 & 15 & 5,71 & 42,85 & 0,05 \\
\hline MPEG; UFPA & 5 & 20 & 14,28 & 57,13 & 0,14 \\
\hline MPEG: UFMG & 2 & 22 & 5,71 & 62,84 & 0,05 \\
\hline MPEG; UFMG; IFPA; UFPA & 1 & 23 & 2,86 & 65,70 & 0,02 \\
\hline UFAM; MPEG; UFPA & 1 & 24 & 2,86 & 68,55 & 0,02 \\
\hline UFMG; MPEG; UFPA & 1 & 25 & 2,86 & 71,41 & 0,02 \\
\hline UFMG; UFPA; MPEG & 1 & 26 & 2,86 & 74,27 & 0,02 \\
\hline UFMG; UFPA; UP'1 & 1 & 27 & 2,86 & 77,13 & 0,02 \\
\hline UFMG; UFJF & 1 & 28 & 2,86 & 79,99 & 0,02 \\
\hline UFMG; UFPA & 1 & 29 & 2,86 & 82,85 & 0,02 \\
\hline UFOPA: UFMG & 1 & 30 & 2,86 & 85,72 & 0,02 \\
\hline UFPA; MPEG & 2 & 32 & 5,71 & 91,42 & 0,05 \\
\hline UFPA; MPEG; IFPA & 1 & 33 & 2,86 & 94,28 & 0,02 \\
\hline
\end{tabular}




\begin{tabular}{lrrrrc} 
UFRA: SEE; MPEG & 1 & 34 & 2,86 & 97,14 & 0,02 \\
UFRA; MPEG & 1 & 35 & 2,86 & 100,00 & 0,02 \\
\hline Legendas: fi - & frequência absoluta; & frp - & frequência relativa porcentual.; \\
frpacm - frequência relativa; porcentual acumulada; $\bar{x}$ média aritmética. \\
Fonte: autores (2018)
\end{tabular}

Os dados indicaram que as parcerias produziram, nos estados do Amazonas e Pará, médias baixas para a extensão territorial de ambos, bem como o número de UC's. No Amazonas, como a Reserva Ducke tem parte de sua área próxima à urbanização, isso pode ter provocado perdas endêmicas que não foram objetos de pesquisa. No Pará, já houve estudo em áreas de verdes remanescentes como, por exemplo, Bosque Rodrigues Alves - Jardim Botânico da Amazônia (MACIEL et al., 2007), Parque Ambiental de Belém (COSTA et al., 2006); Parque Ecológico do Gunma (COSTA; PIETROBOM, 2010); Parque Ecológico Gunnar Vingren (TRAVASSOS et al., 2014), o que pode evidenciar conhecimento um pouco mais amplo quando comparado com o estado do Amazonas.

A análise indicou também que a Universidade Federal de Minas Gerais UFMG, apresenta maior número de parcerias com os órgãos de pesquisa local (8/18), isso deve-se ao fato da existência dos solos ferríferos no Pará (Serra do Carajás) e Minas Gerais (Quadrilátero Ferrífero). Estes estudos podem resultar em comparações quanto as espécies vegetais de Pteridófitas em ambos os locais, o que permitirá a elaboração de políticas de conservação dessa diversidade com mais rigor.

Estudo realizado por Gazda e Quandt (2010), sobre colaboração interinstitucional em pesquisa no Brasil, concluiu que o desenvolvimento de redes e mecanismos de cooperação está fortemente relacionado aos fatores que favorecem o processo inovador, pois unem os aspectos científicos da organização das atividades de pesquisa e desenvolvimento, e a capacidade de criação de conhecimento de cada ator da rede está diretamente relacionada com a interação com outros atores, num processo de aprendizagem coletiva que envolve trocas de conhecimento parcialmente tácito e parcialmente codificado.

Em relação a pesquisas não associadas, a análise dos dados obtidos indicou que sete $(43,75 \%)$ dessas instituições, sem parcerias, produziram $31(46,96 \%)$ pesquisas sobre pteridófitas. Destas, a mais prolífera, foi o Instituto de Botânica de São Paulo - IBSP, com 13 pesquisas $(41,93 \%)$ cujos resultados foram publicados dentro da temporalidade analisada (Figura 3 ).

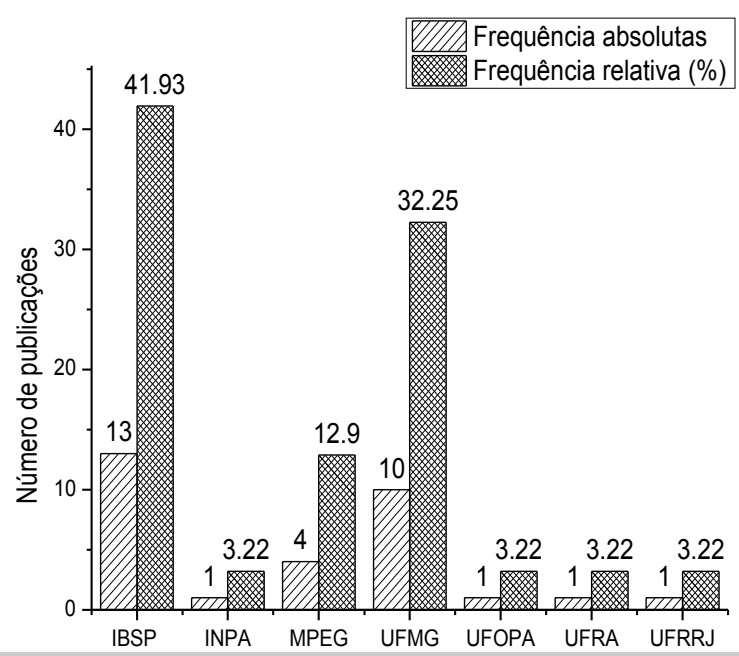

ENCICLOPÉDIA BIOSFERA, Centro Científifigę̧ässonhecer - Goiânia, v.15 n.27; p.68 
FIGURA 3 - Número de pesquisas desenvolvidas com resultados publicados entre 1992-2017.

Fonte: autores (2018).

A análise indicou também que das 13 pesquisas desenvolvidas pelo IBSP, todas foram efetuadas por J. Prado, em 2005, na Reserva Ducke e sobre Pteridófitas. No Pará, a IES mais prolífera, foi o MPEG com quatro pesquisas $(12,9 \%)$. Embora, no biênio 2016-2017, tenha ocorrido pesquisa sobre pteridófitas da Serra dos Carajás Isso já é um avanço, mas de forma pontual.

Os dados indicaram que há presença de instituições do sul e sudeste do país com interesses em parcerias nas pesquisas sobre Pteridophyta no Amazonas e Pará (Ex.: UFMG; UFRRJ). Sobre isso, Sidone et al. (2016) escreveram que o mecanismo de distribuição entre as unidades espaciais é fator crucial em análises regionais. No caso da alocação do produto da atividade científica, tal tarefa não é trivial, principalmente devido à existência de coautorias entre pesquisadores de regiões distintas, já que não é possível associar a publicação a uma única região. Isso foi verificado nas pesquisas realizadas nos dois estados sobre pteridófitas.

Em relação as Unidades de Conservação - UC's, os dados indicaram que, dos 66 artigos analisados, $59(89,39 \%)$, são resultantes de pesquisas sobre pteridófitas. Desse total, $27(40,90 \%)$ ocorreram em duas UC's no Amazonas. No Pará, 32 (48,48\%) foram em oito UC's (Tabela 11).

TABELA 11 - Valores para as frequências absoluta relativa em porcentagem para as pesquisas realizadas em Unidades de Conservação dos estados do Amazonas e Pará.

\begin{tabular}{|l|c|c|c|c|c|c|}
\hline \multicolumn{1}{c}{ Unidades de conservação } & \multicolumn{1}{c}{ UF } & \multicolumn{1}{c}{$\boldsymbol{f i}$} & \multicolumn{1}{c}{$\boldsymbol{f i}_{\text {acm }}$} & \multicolumn{1}{c}{$\boldsymbol{f r p}(\%)$} & \multicolumn{1}{c|}{ frp $_{\text {acm }}$ (\%) } \\
\hline R. F. Adolpho Ducke & AM & 26 & ---- & 97.3 & ------ \\
\hline R. B. Water Egler & AM & 1 & 27 & 3,7 & 100 \\
\hline Área de Pesquisa Ecológica do Rio Guamá & PA & 1 & ---- & 3,12 & ---- \\
Bosque Rodrigues Alves & PA & 1 & 2 & 3,12 & 6,24 \\
Corredor da Biodiversidade do Norte do Pará & PA & 4 & 6 & 12,50 & 18,74 \\
\hline Flona Carajás & PA & 18 & 24 & 56,25 & 74,99 \\
\hline Flona Caxiuanã & PA & 4 & 28 & 12,50 & 87,49 \\
Parque Ambiental de Belém & PA & 1 & 29 & 3,12 & 90,61 \\
Parque Ecológico Gunnar Vingren & PA & 1 & 30 & 3,12 & 93,73 \\
Parque Ecológico do Gunma & PA & 1 & 31 & 3,12 & 96,85 \\
UC - UHE Tucurui & PA & 1 & 32 & 3,12 & 99,97 \\
\hline
\end{tabular}

Legendas: R. F. =- Reserva Floresta; R. B. - Reserva Biológica; UF - Unidade da Federação; fi frequência absoluta; frp - frequência relativa porcentual; fiacm- frequência absoluta acumulada; fracm - frequência relativa acumulada.

Fonte: autores (2018)

A análise estatística quanto as pesquisas em UC's nos dois estados indicou que, em média, nos 27 anos analisados, foram realizadas aproximadamente cinco pesquisas em ambos os estados (Tabela 12).

TABELA 12 - Valores obtidos na análise estatista dos dados em UC's, durante 27 anos, nos Estado do Amazonas e Pará.

\begin{tabular}{l|c}
\hline Dados & Valores obtidos \\
\hline Tamanho da amostra & 11.0 \\
\hline Mínimo & 1,0 \\
\hline Máximo & 26.0 \\
\hline Média & 5.4 \\
\hline Desvio Padrão & 8.5 \\
\hline Fonte: autores (2018)
\end{tabular}


Na pesquisa realizada por Silva et al. (2017), esses autores concluiram que o proposto no art. 12 da Convenção sobre a Diversidade Biológica, letra b, que as pesquisas devem ser estimuladas, promovidas e que contribuam para a conservação e utilização sustentável da diversidade biológica especialmente nos países em desenvolvimento. Isso corrobora com a afirmativa efetuada por Travassos et al., (2014) sobre o conhecimento desses grupos de vegetais que tem proporcionado avanços científicos, principalmente em áreas urbanas e Unidades de Conservação.

\section{CONCLUSÃO}

Os avanços das pesquisas sobre Pteridophyta nos estados do Amazonas e Pará, ainda são incipientes quando comparados com o número de UC's em cada um desses estados. Logo, estas não serviram para intensificar as pesquisas nesses dois estados. Todavia, desde a criação dessas áreas, esses estados têm promovido pesquisas tanto no interior quanto no exterior dessas UC's, para produção de conhecimento sobre a diversidade de espécies, os hábitos e as ações ambientais negativas que atingem esse vegetal, mas houveram novas descobertas de espécies de pteridófitas no Pará.

Com essa insipiência, a conservação da biodiversidade das pteridófitas, fica atrelada apenas a criação de políticas públicas como aquelas elaboradas durante a Rio -92. Logo, a criação das UC's não foi um fator de aceleração da pesquisa, apesar de ter permitido a identificação de novas espécies, que podem ou não exercer papeis como indicadoras de áreas alteradas por presença ou ausência, e dessa forma, contribuir mais eficientemente com a conservação da diversidade biológica de Pteridophyta.

\section{REFERÊNCIAS}

CONFORTO, E. C.; AMARAL, D. C.; SILVA, S. L. D. Roteiro para revisão bibliográfica sistemática: aplicação no desenvolvimento de produtos e gerenciamento de projetos. In: Congresso Brasileiro de Gestão de Desenvolvimento de Produto (CBGDP). 8. Anais... Porto Alegre: UFRGS, 2011, p. 1 - 12. Disponível em:

https://edisciplinas.usp.br/pluginfile.php/2205710/mod_resource/content/1/Roteiro \%20para\%20revis\%C3\%A30\%20bibliogr\%C3\%A1fica\%20sistem\%C3\%A1tica.pdf>.

Acesso em: 20 nov. 2017

COSTA, J. M.; PIETROBOM, M. R. Pteridófitas (Lycophyta e Monilophyta) da llha de Mosqueiro, município de Belém, estado do Pará, Brasil. Boletim do Museu Paraense Emílio Goeldi - Ciências Naturais. Belém, v. 2, n, 3. P. 45 - 55, set/dez. 2007. Disponível em: < http://www.museugoeldi.br/editora/bn/artigos/cnv9n1_2014/first(hall).pdf>. Acesso em: 12 out.2017.

Samambaia e licófitas do Parque Ecológico do Gunma, município de Santa Bárbara do Pará, estado do Pará, Brasil. Rodriguésia. Rio de Janeiro, v. 61, n. 2, p. 223 - 232, apr/jun.2010. DOI: 10.1590/21757860201061200

COSTA, J. M.; SOUZA., M. G. C.; PIETROBOM, M. R. Levantamento florístico das Pteridófitas (Lycophyta E Monilophyta) do Parque Ambiental de Belém (Belém, Pará, 
Brasil). Revista Biologia Neotropical. Goiânia, v, 3, n.1, p. 4 - 12, 2006. DOI: http://dx.doi/org/105216/rbn.v3i1.2813.

FANTINATO, M. Métodos da Pesquisa. São Paulo: USP. 2015.

FERREIRA, S. N.; SAMPAIO. O Pará, apesar de ser o segundo maior estado da região Norte, possui poucos trabalhos desenvolvidos, especificamente com pteridófitas, em seu território., M. J. A. M. Um Pouco da história da Convenção Sobre Diversidade Biológica. In: FERREIRA, S. N.; SAMPAIO, M. J. A. M. (Org.). Biodiversidade e conhecimentos tradicionais associados: implementação da legislação de acesso a repartição de benefícios no Brasil. Brasília: SBPS, 2013, p. 38.

FERENHOF, H. A.; FERNANDES, R. F. Desmistificando a revisão da literatura como base para redação científica. Revista da Associação Catarinense de Bibliotecários. Florianópolis, v. 21, n. 3, p. 550 - 563, ago/nov. 2016. Disponível em: < https://revista.acbsc.org.br/racb/about/editorialPolicies\#focusAndScope>. Acesso em 12 dez.2017.

FIGUEIREDO FILHO, D.B.; PARANHOS, R.; SILVA JÚNIOR, J.A; ROCHA, E.C; ALVES. D. P., O que é, para que serve e como se faz uma meta-analise? Revista Teoria \& Pesquisa. São Carlos, v. 23, n. 2. P. 205 - 228, jul/dez.2014 DOI: http://dx.doi.org/104322/tp2014.018

GARCIA, R. A.; BURGESS, N. D.; CABEZA, C. RAHBEK; ARAÚJO, M. B. Exploring consensus in 21st century projections of climatically suitable areas for African vertebrates. Global Change Biology. n. 18, p. 1253 - 1269.2012. DOI: $10.1111 / \mathrm{j} .1365-2486.2011 .02605$

GAZDA, E.; QUANDT, C. O. Colaboração interinstitucional em pesquisa no brasil: tendências em artigos na área de gestão da inovação. Revista de Administração Eletrônica - ERA eletrônica, v. 9, n.2, p. [s/n]. 2010. Disponível em: http://www.scielo.br/pdf/raeel/v9n2/a10v9n2.pdf. Acesso em: 27 jan.2018.

LEMES, P.; LOYOLA, R. Mudanças climáticas e prioridades para a conservação da biodiversidade. Revista de Biologia Neotropical. Goiânia, v.11, n. 1, p. 47-57, 2014. DOI: http://dx.doi.doc/10.5216./rbn.v11i1.30699

MACIEL, S.; SOUZA, M.G.S.; PIETROBOM, M. R. Licófitas e monilófitas do Bosque Rodrigues Alves Jardim Botânico da Amazônia, município de Belém, estado do Pará, Brasil. Boletim do Museu Paraense Emílio Goeldi. Belém, v. 2, n, 2, p. 69 83, mai/ago.2007. Disponível em: < http://www.museugoeldi.br/editora/bn/artigos/cnv9n1_2014/first(hall).pdf>. Acesso em: 12 out.2017.

MACEDO, M.; BOTELHO, L. L. R.; DUARTE, M. A. T. Revisão bibliométrica sobre a produção científica em aprendizagem gerencial. Revista Gestão e Sociedade. Belo Horizonte, v. 4, n. 8, p. 618 - 639, mai/ago. 2010. DOI: http://dx.doi.org/10.21171/ges.v4i8 
MEDEIROS, I. L.; VIEIRA, A.; BRAVIANO, G.; GONÇALVES, B. S. Revisão Sistemática e Bibliometria facilitadas por um Canvas para visualização de informação. Revista Brasileira de Design da Informação. São Paulo, v. 12, n. 1, p. 93 - 110, jan/abr. 2015. Disponível em: <http://www.infodesign.org.br/infodesign>. Acesso em: 20 out.2017

MEDEIROS, P. S.; FERREIRA, L. V.; COSTA, A. C. L. O impacto do estresse hídrico artificial na comunidade de samambaias e licófitas em um sub-bosque de floresta ombrófila na Amazônia oriental. Boletim do Museu Paraense Emílio Goeldi. Ciências Naturais. Belém, v. 9, n, 1, p. 223 - 230, jan/abr.2014. Disponível em: < http://www.museu-goeldi.br/editora/bn/artigos/cnv9n1_2014/first(hall).pdf>. Acesso em: 12 out.2017.

PEREIRA, G.; GALVÃO, T. F. Etapas de busca e seleção de artigos em revisões sistemáticas da literatura. Epidemiologia e Serviços de Saude. Brasília, v. 23, n, 2, p. 369 - 371, 2014. DOI: htt://dx.doi.org/10.5123/S1679-49742014000200019

PIETROBOM, M. R.; MEDEIRO, P. S.; FONSECA, M. S. S.; MACIEL, S.; SOUZA, M. G. C et al. et al. Contribuição à preservação da Floresta Nacional de Caxiuanã, Pará, Brasil: licófitas e samambaias. Pesquisas Botanica, n, 68, p. $\quad 349-361$, 2015. em:< http://www.anchietano.unisinos.br/publicacoes/botanica/botanica.htm>. Acesso em: 20 dez. 2017

PRODANOV, C. C.; FREITAS, E. C. Metodologia do Trabalho Científico. 2 ed. Rio Grande do Sul: FEEVALE, 2013. ISBN 978-85-7717-158-3

RODRIGUES, S. T.; ALMEIDA, S. S.; ANDRADE, L. H. C.; BARROS, I. C.L.; VAN DEM BERG, M. L. Composição florística e abundância de pteridófitas em três ambientes da bacia do rio Guamá, Belém, Pará, Brasil. Acta Amazonica. Manaus, v..34, n. 1, p. 35 - 42, jan/mar. 2004. http://dx.doi.org/10.1590/S0044-59672004000100005

SAMPAIO, A. F.; SOUZA, M. G. C.; PIETROBOM, M. R. Samambaias da Província Petrolífera de Urucu, Coari, Amazonas, Brasil: Cyatheaceae, Gleicheniaceae, Lygodiaceae, Schizaeaceae, Marattiaceae e Metaxyaceae. Acta Biológica $\begin{array}{lllllll}\text { Catarinense. Joinville, } & \text { v. } & 2, & \text { n. } & 1, & \text { p.55-69, nov. } & \end{array}$ DOI: http://dx.doi.org/10.21726/abc.v1i1

SANTOS, G.C. Análise bibliométrica dos artigos publicados como estudos bibliométricos na História do Congresso Brasileiro de Custos. Pensar contábil. Rio de Janeiro, v.17. n. 62, p. 4 - 13, jan/abr. 2015.Disponível em:< http://www.atena.org.br/revista/ojs-2.2.3-

06/index.php/pensarcontabil/article/viewFile/2527/2151>. Acesso em: 28.01.2018

SIDONE, O.J.G.; HADDAD, E.A.; MENA-CHALCO. A ciência nas regiões brasileiras: evolução da produção e das redes de colaboração científica TransInformação. Campinas, v. 28, n. 1, p. 15-31, 2016. DOI: http://dx.doi.org/10.1590/2318-08892016002800002 
SILVA, AM.; VITAL, M. J. S.; PINHEIRO, L. V. R. Para além do desenvolvimento sustentável: o conhecimento científico como instrumento de proteção da natureza.

Revista Brasileira de Biblioteconomia e Documentação. São Paulo, v. 13, n. esp., p. 543 - 562. Out.2017. Disponível em: https://rbbd.febab.org.br/rbbd/index. Acesso em 23 jan.2018.

SILVA, M. R. P.; ROSÁRIO, S. M. Licófitas e monilófitas (Pteridophyta) da Floresta Nacional de Caxiuanã, estado do Pará, Brasil: chave para as famílias e as espécies de Aspleniaceae e Blechnaceae. Boletim do Museu Paraense Emílio Goeldi. Ciências Naturais. Belém, v. 3, n. 2, p. 151-163, mai/ago. 2008. Disponível em: < http://www.museu-goeldi.br/editora/bn/artigos/cnv9n1_2014/first(hall).pdf>. Acesso em: 12 out.2017.

SLOMSKI, V. G.; PINHEIRO, I. C. B.; MEGLIORINI, E.; FERREIRA, T. A. R. C. A importância da formulação da questão de pesquisa na produção científica em contabilidade: uma discussão a partir de trabalhos publicados no Congresso Brasileiro de Custos no ano de 2009. In: Congresso Brasileiro de custos, 20., 2013, Uberlândia. Anais.... São Leopoldo: Associação Brasileira de Custos, 2013. Disponível em: < https://anaiscbc.emnuvens.com.br/anais/article/download/117/117> Acesso em: 22 jan.2018.

SOUZA, M. C.; GUILLAUMET, J. L.; AGUIAR, I. J. A. Ocorrência e distribuição de pteridófitas na reserva floresta Walter Egler, na Amazônia CENTRAL, Brasil. Acta Amazonica, Manaus, v. 33, n. 4, p. 555 - 562, out/dez. 2003.DOI: http://dx.doi.org/10.1590/S0044-59672003000400003

SOUZA, M. T. S.; RIBEIRO, H. C. M. Sustentabilidade Ambiental: uma Meta-análise da Produção Brasileira em Periódicos de Administração. Revista de Administração Contemporânea. Rio de Janeiro, v. 17, n. 3, p. 368 - 396, mai/jun, 2013. DOI: $h t t p: / / d x . d o i . o r g / 10.1590 / S 1415-65552013000300007$

TRAVASSOS, C. C.; JARDIM, M. A. G.; MACIEL, S. Florística e ecologia de samambaias e licófitas como indicadores de conservação ambiental. Biota Amazônia. Macapá, v. 4, n, 4, p. 40 - 44, jul/dez, 2014. DOI: http://dx.doi.org/10.18561/2179-5746/biotaamazonia.

VANZ, S. A. S.; STUMPF. I. R. C. Procedimentos e ferramentas aplicados aos estudos bibliométricos. Informação \& Sociedade. João Pessoa, v. 20, n.2, p. 67 -75, mai/ago, 2010.Disponível em: http://www.ies.ufpb.br/ojs2/index.php/ies/index. Acesso em: 28 jan.2018 